\title{
Tecnologia e Demanda por Qualificação na Indústria Brasileira*
}

\author{
Naércio Aquino Menezes-Filho** \\ Mauro Rodrigues Jr.***
}

Sumário: 1. Introdução; 2. Teoria e evidência empírica para o Brasil; 3. Análise descritiva; 4. Análise econométrica; 5. Conclusão.

Palavras-chave: tecnologia; educação; emprego; salários.

Códigos JEL: J23; J31.

O objetivo deste artigo é o de estabelecer conexões entre o recente aumento no uso relativo de trabalhadores qualificados (em comparação aos não qualificados) e medidas de tecnologia na manufatura brasileira nas últimas duas décadas. Para tanto, utilizamos a intensidade de P\&D como proxy para progresso técnico. Encontramos evidências de complementaridade entre tecnologia e trabalho qualificado, que parece mais intensa entre 1994 e 1997. Além disso, quando utilizamos a intensidade de P\&D nos Estados Unidos como instrumento para a intensidade de P\&D no Brasil, seu impacto sobre a qualificação aumenta substancialmente, o que nos fornece indícios de que a transferência de tecnologia é um dos fatores que explica o aumento do uso relativo de qualificação no Brasil.

The main aim of this paper is to investigate the relationship between skill upgrading and measures of technology in Brazilian manufacturing for the last two decades. We use R\&D intensity as a proxy for technological change. We find robust evidence of technology-skill complementarity, especially for the period between 1994 and 1997. Furthermore, when U.S. R\&D intensity is used as an instrument for Brazilian R\&D intensity, its impact on skill demand rises threefold. This provides us with evidence that technological transfer is impacting skill-upgrading in Brazil.

\footnotetext{
*Artigo recebido em ago. 2001 e aprovado em set. 2002. Este projeto foi financiado parcialmente pelo Fundo Sassakawa. Naércio Menezes agradece ao CNPq pela bolsa de produtividade em pesquisa $n^{\circ}$. 301236/97-6. Agradecemos a Reynaldo Fernandes, Jorge Saba Arbache, Eduardo Haddad e Antônio Gledson pelos excelentes comentários, e a Nick Bloom, Renata Narita, Fabiana de Felício, Juan Jensen e Carlos Henrique Corseuil pelos dados.

${ }^{* *} \mathrm{IPE} / \mathrm{USP}$.

${ }^{* * *} \mathrm{IPE} / \mathrm{USP}$.
} 


\section{Introdução}

Nas últimas duas décadas, o mercado de trabalho nos países desenvolvidos tem sofrido marcantes modificações: nos Estados Unidos e no Reino Unido, a desigualdade salarial entre trabalhadores qualificados e não qualificados aumentou consideravelmente, enquanto que o desemprego relativo entre tais grupos mostrou relativa estabilidade. Por outro lado, em outros países da Europa Ocidental, o desemprego relativo de não qualificados cresceu ao longo dos anos, enquanto que os diferenciais salariais mantiveram-se relativamente estáveis.

Vários analistas passaram a associar estes fenômenos a uma raiz comum: o aumento da demanda relativa de trabalho qualificado. Estados Unidos e Reino Unido, por possuírem mercados de trabalho pouco regulamentados, teriam o ajuste sobre os salários facilitado. Já o arranjo institucional do mercado dos demais países europeus colocaria maiores dificuldades ao alcance do equilíbrio, fazendo com que o ajuste se desse em maior parte sobre o emprego (Freeman, 1995).

Diversas são as explicações para as causas desses movimentos na demanda, sendo duas mais populares. A primeira delas atribui tais mudanças ao maior contato comercial com os países do Terceiro Mundo, sobretudo a partir dos processos de liberalização comercial destas economias iniciados nos anos 80. A justificativa teórica está no modelo de Heckscher-Ohlin, o qual implica que cada país deve especializar-se em produtos intensivos no fator de produção que possui em maior abundância. Os países desenvolvidos, assim, tenderiam a especializar-se em produtos intensivos em trabalho qualificado, o que aumentaria a demanda relativa deste fator. O resultado simétrico ocorreria em países subdesenvolvidos. ${ }^{1}$

A interpretação alternativa a esta baseia-se no padrão tecnológico dos últimos anos, através de eventos como a entrada de computadores no local de trabalho, novas tecnologias de informação etc. Supõe-se que estes choques tecnológicos seriam enviesados para o fator trabalho qualificado, o que aumentaria sua demanda em detrimento do trabalho não qualificado.

A observação dos referidos fatos e suas possíveis explicações motivaram o aparecimento de uma vasta literatura empírica para os países desenvolvidos. ${ }^{2}$ De um modo geral, conclui-se que o impacto do comércio internacional sobre o mercado de trabalho destes países seria relativamente pequeno, ganhando força a tese relacionada à mudança tecnológica. Algumas constatações contribuem para esta conclusão como, por exemplo: observa-se que o aumento da utilização relativa de trabalho qualificado não se acha circunscrito a setores produtores de tradables;

\footnotetext{
${ }^{1}$ Ver Wood (1994) para uma apresentação mais pormenorizada do argumento.

${ }^{2}$ Artigos como Burtless (1995) e Arbache (2000) oferecem revisões desta literatura.
} 
mesmo em países em que desigualdade se ampliou, diversos setores mais desagregados apresentaram aumento do uso relativo do fator que ficou relativamente mais caro, o trabalho qualificado; não se verifica que os preços dos bens intensivos em baixa qualificação caíram mais rapidamente que os demais nestes países (price puzzle). (Arbache, 2000, Desjonqueres et alii, 1999)

Talvez um dos motivos mais importantes para o enfraquecimento da interpretação ligada ao comércio internacional esteja na observação destes fenômenos para os países em desenvolvimento. Wood (1997) constata que diversos países latino-americanos registraram ampliação da desigualdade salarial nas últimas duas décadas, ao contrário do que teria ocorrido nas economias do Leste Asiático nos anos 60 e 70, época em que estas nações adotaram políticas de orientação para o exterior. ${ }^{3}$ Berman e Machin (2000) encontram evidências fortes de que a demanda relativa de qualificados acelerou-se nos anos 80 tanto em países de alta renda como principalmente em países de renda média (entre os quais estão vários países em desenvolvimento), enquanto que a evidência para países de baixa renda é mais fraca.

Wood (1997) argumenta que a presença de choques tecnológicos enviesados para trabalhadores qualificados poderia estar explicando esse comportamento. ${ }^{4}$ É preciso notar que esta interpretação não isenta o comércio internacional de efeitos sobre o mercado de trabalho. A abertura possibilita o acesso a bens de capital mais avançados, enquanto que o aumento da concorrência pode levar as empresas locais a adotarem métodos mais modernos. Se a tecnologia for enviesada para o trabalho qualificado, este fator certamente terá sua demanda magnificada. Além disso, a liberalização financeira, que normalmente acompanha os processos de abertura comercial, permite que a difusão da tecnologia se aprofunde, sobretudo a originária de países desenvolvidos. A idéia é que a mudança tecnológica seria não apenas enviesada para o trabalho qualificado, mas tenderia a espalhar-se, não sendo privilégio de um pequeno conjunto de países (Berman et alii, 1998, Krugman, 1995).

\footnotetext{
${ }^{3}$ As evidências referentes à América Latina fornecidas por Wood estão fortemente baseadas nos trabalhos de Donald J. Robbins. Por exemplo, em Robbins (1996), este pesquisador verifica que em todos os países por ele analisados (Argentina, Chile, Colômbia, Costa Rica, México, Filipinas, Taiwan e Uruguai) com exceção da Argentina, houve aumento da demanda por qualificados na seqüência de liberalizações comerciais.

${ }^{4}$ Wood (1997) ressalta que o aumento da demanda relativa de trabalho qualificado nestes países pode estar ligado à entrada no comércio internacional de economias com alta dotação de trabalho não qualificado, tais como Índia e China.
} 
Este artigo pretende trazer essa discussão para o Brasil, dando ênfase especial ao setor manufatureiro. A evidência sobre o assunto é ainda bastante preliminar para este país, apesar de estar crescendo rapidamente. O caso brasileiro é particularmente interessante, uma vez que sua economia quase autárquica da década de 80 passou por fortes modificações no início dos anos 90 que levaram ao rápido e brutal estreitamento dos laços comerciais com o exterior, através de quedas em tarifas e barreiras não tarifárias em diversos setores da atividade econômica. Ao mesmo tempo, o país tornou-se mais aberto aos fluxos internacionais de capital, o que provavelmente facilitou a absorção de tecnologia dos países desenvolvidos.

Nossa principal inovação está na utilização de medidas de progresso técnico e capital físico com o objetivo de captar seus efeitos sobre o emprego de trabalhadores qualificados vis-à-vis trabalhadores não qualificados. A metodologia aqui utilizada baseia-se na desenvolvida por Berman et alii (1994), a qual gerou uma série de artigos correlatos. ${ }^{5}$ A idéia desses autores consiste em, primeiramente, tentar decompor a variação no uso de trabalho qualificado (em um conjunto de setores) nos componentes intrasetorial e intersetorial, o que permite fazer algumas observações sobre as causas do aumento da demanda por qualificação. Adicionalmente, tenta-se explicar este comportamento mediante uma série de variáveis, especialmente por uma medida de tecnologia como intensidade da atividade de pesquisa e desenvolvimento $(\mathrm{P} \& \mathrm{D})$ ou uso de computadores no local de trabalho.

Organiza-se o presente artigo da seguinte forma. A seção 2 apresenta o modelo de Heckscher-Ohlin em uma versão simplificada, com vistas a justificar teoricamente os argumentos utilizados ao longo do texto, e resume algumas evidências empíricas relacionadas ao Brasil. A seção 3 encarrega-se de traçar uma análise descritiva dos dados utilizados, enfatizando a decomposição a que nos referimos anteriormente. A seção 4, por sua vez, trata de estimar um modelo nos moldes de Berman et alii (1994) - mais especificamente o modelo proposto por Machin et alii (1996) - tendo a intensidade de P\&D como proxy para mudança tecnológica. Adicionalmente, estima-se esse mesmo modelo, mas utilizando dados de intensidade de P\&D dos Estados Unidos como instrumento para a medida de tecnologia brasileira, o que permite fazer algumas considerações sobre a influência da transferência de tecnologia sobre o uso de qualificação no Brasil. A seção 5, por fim, traz a conclusão.

\footnotetext{
${ }^{5}$ Ver Johnson et alii (1999) e Chennells e Van Reenen (1999) para uma revisão.
} 


\section{Teoria e Evidência Empírica para o Brasil}

A base para interpretar as mudanças ocorridas no mercado de trabalho a partir de choques tecnológicos e abertura comercial está no modelo de Heckscher-Ohlin. ${ }^{6}$ Nesta seção apresenta-se este modelo e seus principais resultados a partir de uma versão bastante simplificada do mesmo. Além disso, alguns trabalhos empíricos para o Brasil são descritos.

Consideram-se economias com dois setores distintos, cada um produzindo apenas um bem tradable (havendo, portanto, dois bens, bem 1 e bem 2) por meio de dois fatores homogêneos - trabalho qualificado e trabalho não qualificado combinados através de funções de produção neoclássicas com retornos constantes de escala. O setor 1 é relativamente intensivo no fator trabalho qualificado, para quaisquer preços dos insumos. As firmas de cada indústria maximizam lucro em concorrência perfeita, e tomam como dados os preços dos fatores.

O mercado de fatores está sempre em equilíbrio e livre de quaisquer imperfeições. Os fatores possuem mobilidade plena entre os setores (de modo que seus preços são os mesmos para toda a economia), mas não podem mover-se para qualquer outra economia, e são ofertados de maneira completamente inelástica.

Além disso, existem dois países, Norte e Sul, com preferências idênticas e homotéticas, mesmas condições tecnológicas, distintos apenas em suas dotações relativas de fatores: o Norte é relativamente abundante em trabalho qualificado e o Sul é relativamente abundante em trabalho não-qualificado. Nenhuma das duas economias possui poder para afetar os preços dos produtos finais; a tecnologia disponível e o estoque de fatores também lhes são exógenos.

Um resultado fundamental para entender os impactos da liberalização comercial sobre o mercado de trabalho é o Teorema de Stolper-Samuelson, o qual estabelece a ligação entre preços relativos dos bens finais e preços relativos dos fatores. A idéia é que aumentos no preço relativo de um bem acarretarão aumentos na remuneração real do fator usado intensivamente em sua produção e queda na remuneração real do outro fator.

Em outras palavras, a elevação no preço do bem 2, por exemplo, dado o preço do bem 1, provoca um estímulo à expansão deste setor em detrimento do setor 1, fazendo com que haja um deslocamento de fatores da indústria 1 para a indústria 2. Supondo que esta última seja intensiva em trabalho não qualificado, gera-se um excesso de demanda por este insumo e um excesso de oferta de trabalho qualificado, causando um aumento na remuneração do primeiro e uma queda a remuneração do último. Com o trabalho não-qualificado relativamente mais caro, as firmas

\footnotetext{
${ }^{6}$ Ver Jones (1965) para um tratamento formal do modelo descrito nesta seção.
} 
de ambos os setores tenderão a substituí-lo pelo outro fator, tornando-se mais intensivas em trabalho qualificado. Este processo termina quando as condições de lucro zero são repostas, eliminando incentivos à expansão do produto: o novo equilíbrio apresenta maior produto do setor 2 , menor produto do setor 1 , trabalho não qualificado relativamente mais caro e menor utilização relativa deste fator por parte das firmas.

A partir daí torna-se mais simples entender os impactos da abertura sobre os dois fatores. Em autarquia, o preço relativo do trabalho qualificado é mais alto no Sul, dado que é relativamente escasso, o que faz com que o preço relativo do bem 1, intensivo neste fator, seja maior que no outro país. A abertura conduz à equalização dos preços dos produtos, fazendo com que a remuneração relativa do trabalho qualificado caia (eleve-se) no Sul (Norte). Paralelamente, cada país especializa-se nos bens intensivos nos fatores que possuem em maior abundância (Teorema de Heckscher-Ohlin).

Os efeitos de mudanças tecnológicas exógenas são muito semelhantes a aumentos de preços. Como apontado por Leamer (1994), a presença de progresso técnico enviesado para trabalho qualificado, por si só, não é suficiente para gerar aumento na remuneração relativa deste fator. O que importa, em uma economia tomadora de preços dos produtos, é o viés setorial. Por exemplo, se o setor 1 experimenta progresso técnico de qualquer caráter (dadas as condições tecnológicas do setor 2), tudo se processa como um aumento do preço de seu produto: o custo unitário cai abaixo do preço, estimulando a expansão da indústria 1 e retração da outra. Como o setor 1 é intensivo em trabalho qualificado, este fator encarecer-se-á em relação ao trabalho não qualificado. O setor 2 ficará, frente a isto, mais intensivo em trabalho não qualificado, mas o efeito final sobre a intensidade fatorial do setor 1 dependerá do tipo de progresso técnico ocorrido. Nos casos Hicks-neutro e enviesado para o trabalho não-qualificado, a mudança de preços relativos dos fatores não atua na direção contrária da alteração tecnológica, fazendo com que esta indústria empregue mais intensivamente o fator trabalho não-qualificado. Todavia, isto não ocorre quando o progresso técnico é viesado para o trabalho qualificado, o que torna ambíguo o resultado líquido.

Por outro lado, se o progresso técnico tiver impacto idêntico nas duas indústrias, não haverá mudanças na remuneração relativa: o efeito semelhante ao aumento de preços será igual em ambos os setores, de modo que não haverá impactos sobre o "preço relativo". Tudo funciona como um aumento na dotação de fatores. Por exemplo, um choque de produtividade enviesado para o trabalho qualificado corresponde a uma elevação do estoque deste fator, levando à expansão do produto 
do setor 1 (intensivo neste tipo de trabalho) e retração do setor $2 .^{7} \mathrm{O}$ impacto sobre as intensidades fatoriais estará condicionado apenas ao viés do progresso técnico, já que a remuneração relativa não sofreu alterações.

Todavia, esses resultados só são válidos sob a hipótese de pequena economia aberta. Alguns autores, como Krugman (1995), argumentam que tal modelo baseia-se no fato de o progresso técnico ocorrer isoladamente no país em foco, ao passo que seria mais realista supor que estes fenômenos sejam comuns a um conjunto suficientemente grande de economias. ${ }^{8}$ Desta forma, o problema poderia ser tratado mais adequadamente através de um modelo de economia fechada, em que os preços são endógenos e a demanda passa a ser importante para determinar o equilíbrio.

Nesse caso, o viés fatorial ganha relevância. A ocorrência de mudanças tecnológicas enviesadas para trabalho qualificado, qualquer que seja o viés setorial, faz com que a remuneração relativa deste fator aumente (Krugman, 1995, Berman et alii, 1998). É necessário somente que os preços sejam de alguma maneira afetados por condições internas - por exemplo, quando há diferenciação internacional de produtos ou quando um país for suficientemente grande para alterar os preços externos (Johnson et alii, 1999) - para que estes resultados sejam relevantes.

Talvez pela proximidade temporal das reformas comerciais, a literatura empírica para o Brasil é bastante recente e preliminar, não sendo possível ainda apontar para alguma conclusão mais consensual. Contudo, o interesse sobre o assunto vem crescendo rapidamente nos últimos anos.

Por exemplo, Fernandes e Menezes-Filho (2000) reportam tendência de aumento dos retornos da educação superior (e redução dos retornos dos demais níveis) entre 1983 e 1997 nas mais importantes regiões metropolitanas. Ao mesmo tempo, a parcela de indivíduos deste tipo aumentou, podendo sinalizar a ocorrência de deslocamentos na demanda por trabalhadores com nível educacional mais alto (mais qualificados). ${ }^{9} \mathrm{Na}$ mesma linha, Green et alii (2000) encontram tendência de crescimento da demanda por mão-de-obra com educação superior (com relação a indivíduos com educação elementar), principalmente após 1992.

\footnotetext{
${ }^{7}$ Este resultado está relacionado a aumentos exógenos na dotação de fatores de uma economia, para dadas condições tecnológicas (Teorema de Rybczynski). Por exemplo, um aumento no estoque de trabalho qualificado leva a uma expansão do setor 1 (intensivo neste fator) e retração do setor 2, sem que haja impactos sobre as remunerações dos fatores.

${ }^{8}$ Note-se que o modelo de Heckscher-Ohlin supõe tecnologias idênticas entre os países, o que fortalece o argumento de Krugman.

${ }^{9}$ Todavia, para o início dos anos 90 (1990-91), simultaneamente à reforma comercial, os autores registram quedas consideráveis nos retornos em todos os níveis educacionais, com exceção do nível mais baixo.
} 
Por outro lado, Machado e Moreira (2000) fornecem indícios de que as mudanças na demanda relativa de trabalho teriam favorecido mais os trabalhadores não qualificados entre 1990 e 1993, o que poderia ter sido causado pela abertura. Entretanto, os autores não chegam a evidências de que o aumento nas importações teria sido responsável por este deslocamento na demanda. Já Arbache e Corseuil (2000), com base em uma amostra de setores manufatureiros, verificam que a participação de cada indústria no emprego total é negativamente correlacionada com a penetração de importações. Mais importante, este impacto negativo revelou-se mais forte em setores menos intensivos em qualificação, contrariando os resultados do modelo de Heckscher-Ohlin para um país, em tese, com baixa dotação de trabalho qualificado.

\section{Análise Descritiva}

Esta seção busca descrever o perfil temporal da utilização relativa de trabalho qualificado no Brasil, de acordo com os dados da PNAD de 1981 a 1997. Primeiramente enfocam-se os setores agregados, com vistas a fazer algumas considerações sobre a importância de movimentos na demanda relativa de trabalho qualificado nos últimos anos. A seguir, decompõe-se a variação do uso relativo de trabalho qualificado nos componentes intersetorial e intrasetorial, o que permite analisar a influência das possíveis causas do comportamento desta variável.

Utilizam-se somente indivíduos de 16 a 64 anos que registrem algum rendimento do trabalho principal. Trabalhadores com 11 ou mais anos completos de estudo foram classificados como qualificados, enquanto que os demais foram classificados como não qualificados. Todas as medidas construídas a partir desses dados consideram os pesos da PNAD.

\subsection{Setores agregados: oferta e demanda relativa de qualificados}

O gráfico da figura 1 apresenta a evolução temporal, no agregado, da proporção do emprego composta por trabalhadores qualificados (emprego relativo), assim como a parcela da massa salarial total alocada a este fator (massa salarial relativa). Observa-se diretamente que o uso relativo de trabalho qualificado é crescente em todos os anos, sendo as transformações na alocação entre os dois fatores bastante marcantes: em 1981, 16,34\% dos indivíduos da amostra pertenciam à categoria trabalho qualificado, enquanto que $38,81 \%$ da massa salarial era alocada para este insumo; em 1997, estes números sobem para 27,09\% e 53,18\% respectivamente. 
Figura 1

Evolução temporal da utilização da massa salarial e da oferta relativa de trabalho qualificado (agregado)

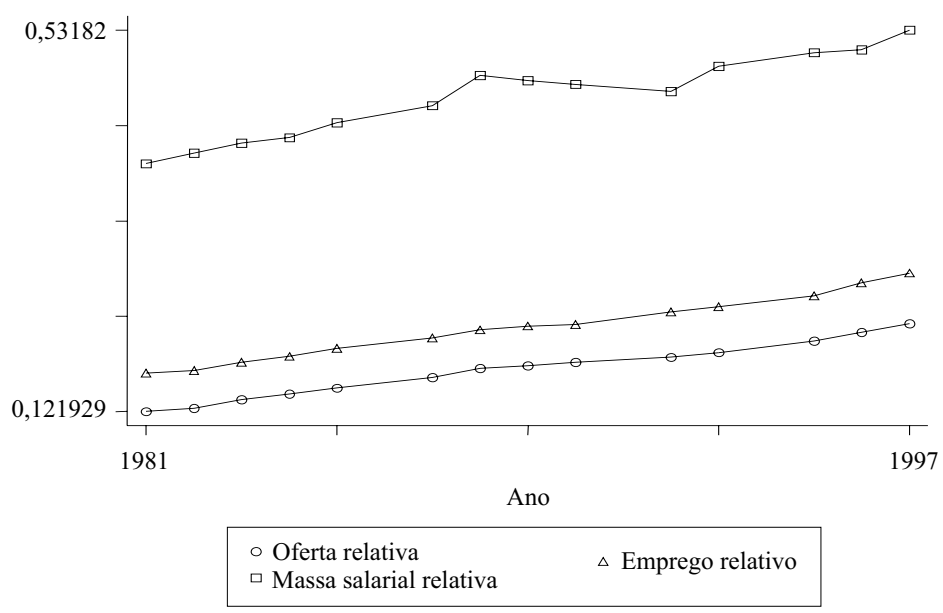

O padrão de crescimento conjunto das séries de emprego e massa salarial relativa pode sugerir duas interpretações. Por um lado, a maior utilização de qualificados pode estar sendo causada pelo aumento na oferta relativa desse insumo. Nesse caso, observar-se-ia queda na remuneração relativa do trabalho qualificado, seguida de aumento do emprego relativo. No entanto, este crescimento só é acompanhado pela massa salarial relativa se a elasticidade-substituição entre trabalho qualificado e trabalho não qualificado for superior a 1, de modo que o emprego relativo aumente mais que proporcionalmente à redução do salário relativo (isto é, uma alta substituição). O aumento da oferta de qualificados é uma característica do período em foco, como pode ser visualizado na figura 1, na série de oferta relativa, a qual considera todos os indivíduos entre 16 e 64 anos, que apresentem ou não rendimentos do trabalho.

Por outro lado, se a restrição sobre a elasticidade-substituição não for verdadeira, outros fatores estarão influenciando o maior uso relativo de trabalho qualificado que não o preço, fatores estes associados à demanda relativa por qualificação. Em outras palavras, para dados preços dos fatores, as firmas teriam maior incentivo a utilizar qualificados, o que magnificaria tanto o emprego relativo de trabalho qualificado, como a massa salarial alocada a esse fator.

As características do agregado podem também ser reconhecidas nos 11 ramos de atividade da PNAD (figura 2). Para todos eles é possível visualizar a mesma tendência de aumento da utilização de trabalho qualificado no tempo (tanto no emprego como na massa salarial), apesar das diferenças de magnitude entre tais ramos. 
O mesmo argumento a respeito da elasticidade-substituição dos dois fatores é também válido aqui. Se a variação do emprego de cada ramo fosse dada somente pela oferta relativa de qualificados, em todos eles a elasticidade-substituição deveria ser maior que 1. É certo que o grande aumento da oferta importa para explicar o deslocamento do uso de qualificação. Entretanto, movimentos relacionados a uma maior demanda por qualificados provavelmente são também relevantes: ainda que no agregado a elasticidade-substituição seja maior que 1, é difícil acreditar que todos os ramos de atividade apresentem tal característica.

Figura 2

Parcela do número de trabalhadores e da massa salarial alocados a qualificação por ramo de atividade

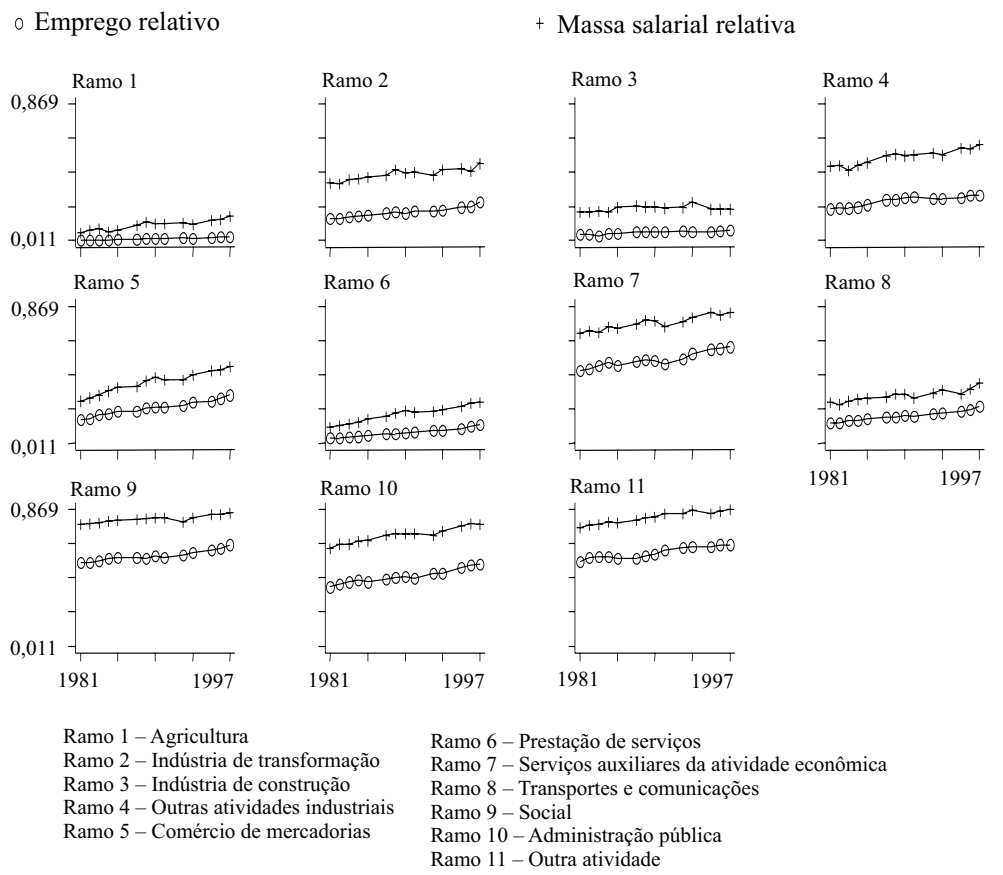

Observam-se tais movimentos conjuntos de emprego e massa salarial relativa mesmo em graus de desagregação ainda maiores. A figura 3 mostra que, para a grande maioria das 143 atividades econômicas da PNAD (ramos de negócio) que puderam ser acompanhadas em todo o período 1981-97, massa salarial e emprego variaram no mesmo sentido. Além disso, para todas estas atividades a correlação entre as duas variáveis (não reportadas) em questão mostrou-se positiva e, na grande maioria dos casos, significante e com alta magnitude. 
Figura 3

Mudanças no emprego e na massa salarial relativa entre 1981 e 1997

(atividades econômicas)

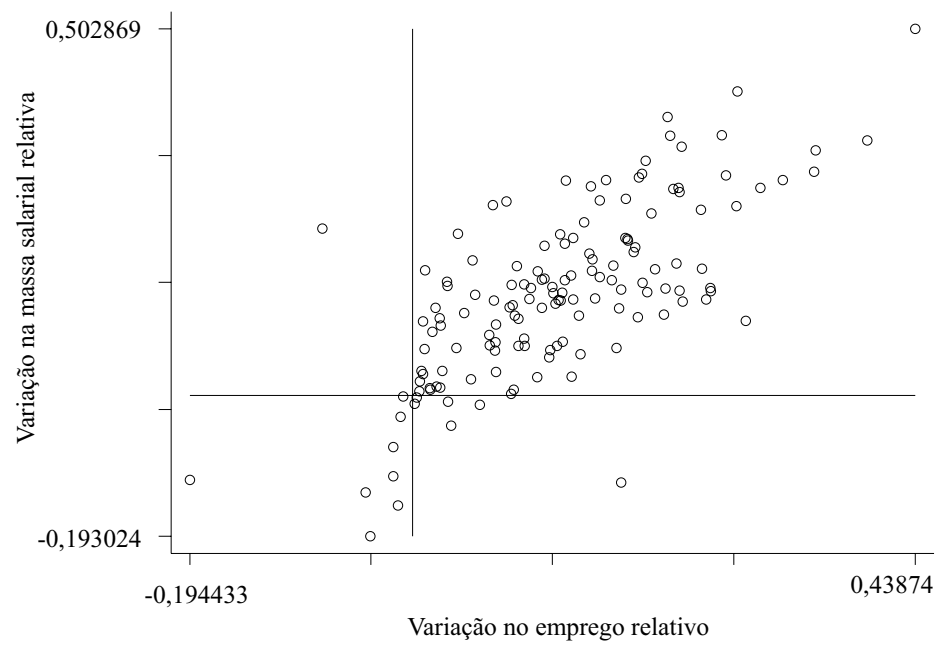

Uma forma de mensurar a demanda relativa por trabalhadores qualificados segue da idéia de Autor et alii (1998). Supõe-se que a economia possua uma função de produção agregada do tipo CES, mediante a qual se combina trabalho qualificado e trabalho não qualificado. Das condições de custo mínimo decorre que:

$$
\ln \left(\frac{w_{t}^{S}}{w_{t}^{U}}\right)=\frac{1}{\sigma}\left[D_{t}-\ln \left(\frac{S_{t}}{U_{t}}\right)\right]
$$

em que:

$w_{t}^{S} / w_{t}^{U}$ é a razão entre os salários médios do trabalho qualificado e do trabalho não qualificado no ano $t$;

$S_{t} / U_{t}$ é a oferta de trabalho qualificado com relação a trabalho não qualificado em $t$; $\sigma$ é a elasticidade-substituição entre os dois fatores;

$D_{t}$ é o log da demanda de trabalho qualificado com relação a trabalho não qualificado em $t$.

Resolvendo para a demanda relativa:

$$
D_{t}=\ln \left(\frac{w_{t}^{S} S_{t}}{w_{t}^{U} U_{t}}\right)+(\sigma-1) \ln \left(\frac{w_{t}^{S}}{w_{t}^{U}}\right)
$$

Na figura 4 expõem-se os resultados da aplicação da equação (1) para a amostra como um todo, utilizando valores de $\sigma$ sugeridos por Autor et alii (1998). Pode- 
se perceber a tendência de aumento da demanda relativa por trabalhadores mais educados no período em foco mesmo para $\sigma>1$, situação em que o aumento simultâneo de emprego e massa salarial relativa poderia ser atribuído tão-somente a variações na oferta de qualificação. Ressalte-se que esses resultados não levam em consideração mudanças na composição da força de trabalho, devendo ser encarados apenas como medida descritiva. ${ }^{10}$

Figura 4

Demanda relativa de trabalho qualificado
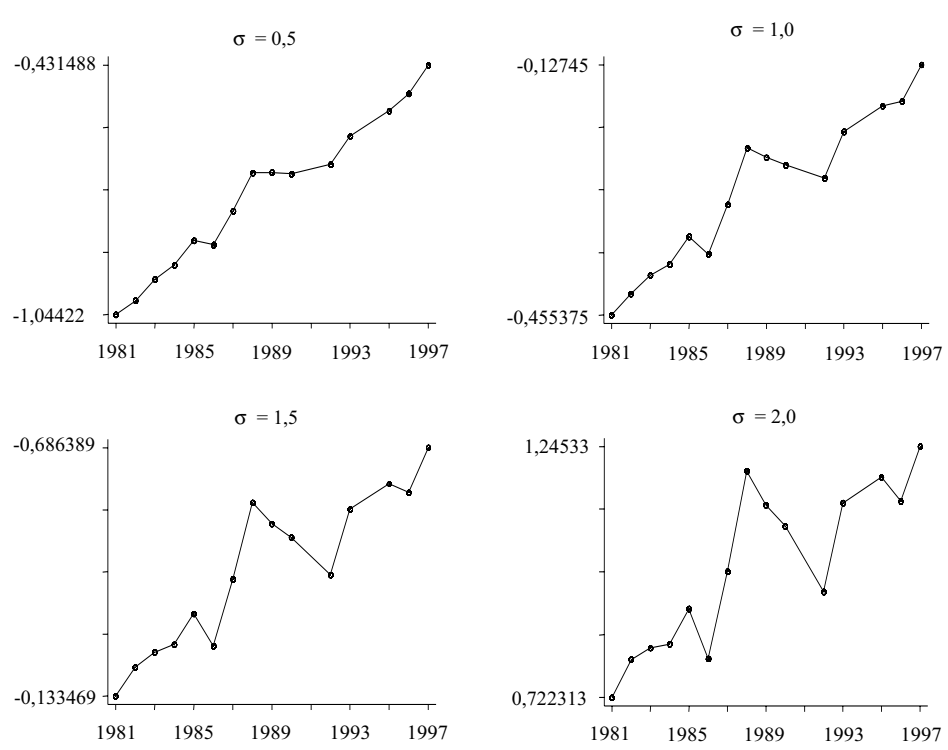

Em suma, a crescente utilização relativa de trabalhadores mais educados é uma característica das últimas duas décadas, tanto para o agregado como para a maioria dos setores desagregados, e movimentos na demanda relativa por trabalhadores deste tipo são aparentemente importantes para explicar este comportamento.

É preciso ressaltar, ainda, que este aumento crescente no uso de qualificação particularmente válido para a grande maioria dos setores que compõem a manufatura (indústria de transformação), a qual passamos a enfocar no decorrer do artigo. A tabela 1 ilustra este ponto, trazendo informações acerca da utilização relativa de fatores - e como esta evoluiu no tempo - para as 23 atividades econômicas manufatureiras que puderam ser acompanhadas ao longo do período 1981-97. As indústrias estão ordenadas decrescentemente de acordo com o emprego relativo em 1981.

\footnotetext{
${ }^{10}$ Green et alii (2000) realizam o mesmo exercício (com trabalhadores com nível universitário versus trabalhadores com escolaridade elementar), mas levando em conta parcialmente as mudanças na composição. Apesar disso, seus resultados são bastante semelhantes aos nossos.
} 


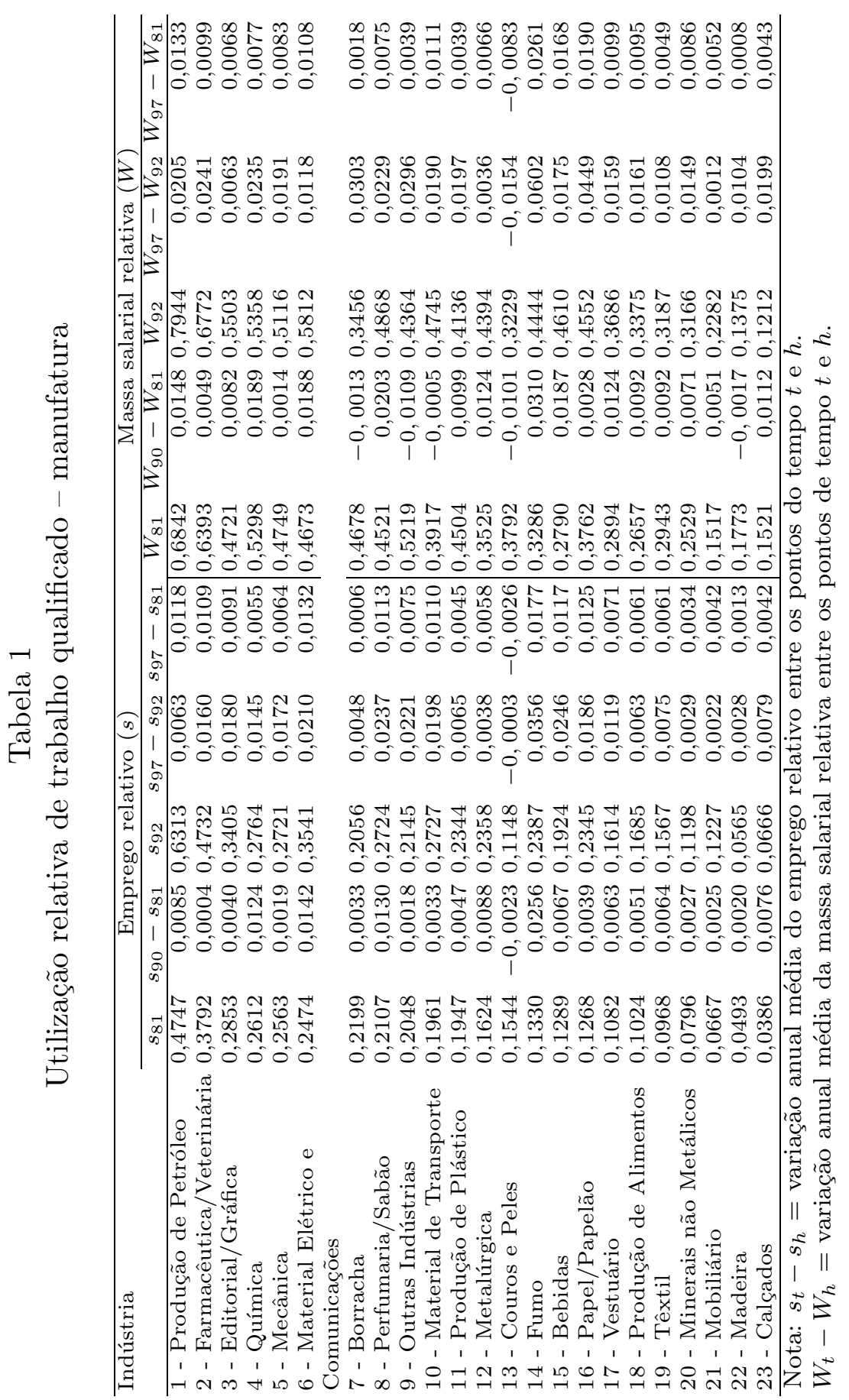




\subsection{Decomposição da variação do uso relativo de qualificados: efeito escala e efeito substituição}

É possível avaliar o aumento no emprego relativo de qualificados (como o verificado nos dados ao longo desta seção) entre dois pontos do tempo através da seguinte decomposição (Berman et alii, 1994):

$$
\Delta s=\underbrace{\sum_{i} \bar{e}_{i} \Delta s_{i}}_{\text {efeito substituição }}+\underbrace{\sum_{i} \bar{s}_{i} \Delta e_{i}}_{\text {efeito escala }}
$$

em que:

$s_{i}$ é a parcela do emprego do setor $i$ composta por trabalhadores qualificados;

$s$ é a parcela do emprego total dos setores composta por trabalhadores qualificados;

$e_{i}$ é a parcela do emprego total dos setores alocada no setor $i$;

$\Delta$ é o operador diferença (entre dois determinados pontos do tempo).

A barra acima das variáveis denota a média temporal destas no período em questão. De acordo com a equação (2), a variação no emprego relativo de trabalho qualificado pode ser decomposta em dois termos:

- Efeito substituição, ou seja, para uma mesma alocação de fatores entre os setores, uma maior utilização relativa de trabalho qualificado por parte das firmas, dada, por exemplo, pelo fato de algum insumo ter ficado relativamente mais barato ou mais produtivo;

- Efeito escala, ou seja, para um dado uso relativo dos fatores, uma expansão relativa dos setores intensivos em trabalho qualificado.

Efetua-se a decomposição acima não só para a manufatura (setores normalmente tidos como tradables), mas também para alguns setores considerados nontradables - indústria de construção e setores relacionados à provisão de serviços. ${ }^{11}$ Focaliza-se também dois subperíodos: 1981-90 (pré-abertura) e 1992-97 (pósabertura). Os resultados estão expostos na tabela 2.

\footnotetext{
${ }^{11} \mathrm{~A}$ denominação non-tradables foi atribuída a 62 ramos de atividade da PNAD (os quais puderam ser comparados durante todo o período 1981-97) referentes a comércio de mercadorias, prestação de serviços, serviços auxiliares à atividade econômica, transportes e comunicações, indústria de construção, além de atividades relacionadas ao setor financeiro.
} 
Tabela 2

Decomposição entre efeito substituição e efeito escala - emprego relativo

(em pontos percentuais)

\begin{tabular}{|c|c|c|c|c|c|c|}
\hline \multicolumn{7}{|c|}{ Manufatura } \\
\hline \multirow[b]{2}{*}{ Período } & Variaçãc & Total & Efeito Su & stituição & Efeito Escala & \multirow{2}{*}{\begin{tabular}{|c|} 
Efeito \\
substituição \\
$\%$
\end{tabular}} \\
\hline & $\begin{array}{l}\text { Total no } \\
\text { período }\end{array}$ & $\begin{array}{l}\text { Média } \\
\text { anual }\end{array}$ & $\begin{array}{l}\text { Total no } \\
\text { período }\end{array}$ & $\begin{array}{c}\text { Média } \\
\text { anual }\end{array}$ & $\begin{array}{l}\text { Total no Média } \\
\text { período anual }\end{array}$ & \\
\hline 19 & 4,89 & 0,54 & 5,10 & 0,57 & $-0,22 \quad-0,02$ & $104,35 \%$ \\
\hline & 5 & 1,00 & 5 & 1 , & 0,00 & $99,82 \%$ \\
\hline & 9,94 & 0,62 & 10,42 & 0,65 & $-0,48 \quad-0,03$ & $104,83 \%$ \\
\hline \multicolumn{7}{|c|}{ Outros } \\
\hline \multirow[b]{2}{*}{ Período } & \multicolumn{2}{|c|}{ Variação Total } & \multicolumn{2}{|c|}{ Efeito Substituição } & Efeito Escala & \multirow{2}{*}{\begin{tabular}{|c} 
Efeito \\
substituição \\
$\%$
\end{tabular}} \\
\hline & $\begin{array}{l}\text { Total no } \\
\text { período }\end{array}$ & $\begin{array}{l}\text { Média } \\
\text { anual }\end{array}$ & $\begin{array}{l}\text { Total no } \\
\text { período }\end{array}$ & $\begin{array}{l}\text { Média } \\
\text { anual }\end{array}$ & $\begin{array}{l}\text { Total no Média } \\
\text { período anual }\end{array}$ & \\
\hline 0 & 5,02 & 0,56 & 4,99 & 0,55 & 0,00 & $99,38 \%$ \\
\hline & 3,77 & 0,75 & 4,13 & 0,83 & $-0,36$ & $109,51 \%$ \\
\hline $1981-97$ & 9,49 & 0,59 & 10,42 & 0,65 & $-0,93$ & $109,73 \%$ \\
\hline
\end{tabular}

É notável que os valores para o efeito escala são bastante limitados para os setores manufatureiros (tradables). Tal evidência parece contrariar a idéia que a abertura comercial teria impactos significativos sobre o mercado de trabalho, na medida em que deveria ensejar uma forte realocação de fatores dos setores intensivos em trabalho qualificado para setores intensivos em trabalho não-qualificado, ou seja, um efeito escala significativamente negativo em países como o Brasil (relativamente abundante em trabalhadores não qualificados). Em particular, verifica-se um efeito escala pequeno, porém positivo no período pós-liberalização comercial (1992-97) - ou seja, um pequeno movimento de fatores para indústrias mais intensivas em qualificação - e negativo no período anterior.

Com relação aos non-tradables, pode-se observar que o efeito escala registrou sinal negativo no período 1992-97, e mostrou-se relativamente mais importante do que nos setores manufatureiros. Tal fato aparentemente reforça a idéia de que o estreitamento das relações comerciais com o resto do mundo teria pouco a contribuir para o aumento da utilização relativa de trabalho qualificado nas últimas décadas.

$\mathrm{Na}$ formulação da equação (2), no entanto, o efeito substituição incorpora também a reação das firmas a mudanças nos preços dos fatores. Uma maneira de contornar parcialmente isto consiste em utilizar a parcela da massa salarial alocada a trabalhadores qualificados ao invés do emprego proporcional deste fator, uma vez que, se a elasticidade substituição entre os dois insumos for próxima de 1, variações nas remunerações dos fatores causam pequenas alterações na alocação da massa salarial entre os mesmos. Os resultados seguem na tabela 3. 
Tabela 3

Decomposição entre efeito substituição e efeito escala - massa salarial relativa

(em pontos percentuais)

\begin{tabular}{|c|c|c|c|c|c|c|}
\hline \multicolumn{7}{|c|}{ Manufatura } \\
\hline \multirow[b]{2}{*}{ Período } & Variaçã & Total & Efeito Su & stituição & Efeito Escala & \multirow{2}{*}{$\begin{array}{c}\text { Efeito } \\
\text { substituição } \\
\%\end{array}$} \\
\hline & $\begin{array}{l}\text { Total no } \\
\text { período }\end{array}$ & $\begin{array}{l}\text { Média } \\
\text { anual }\end{array}$ & $\begin{array}{l}\text { Total no } \\
\text { período }\end{array}$ & $\begin{array}{l}\text { Média } \\
\text { anual }\end{array}$ & $\begin{array}{l}\text { Total no Média } \\
\text { período anual }\end{array}$ & \\
\hline 19 & 6,88 & 0,76 & 7,44 & 0,83 & $-0,57 \quad-0,06$ & $108,20 \%$ \\
\hline & 7 & 1. & 7,60 & 1 , & $-0,43$ & $105,95 \%$ \\
\hline & 11,97 & 0,75 & 13,06 & 0,82 & $-1,09 \quad-0,07$ & $109,05 \%$ \\
\hline \multicolumn{7}{|c|}{ Non-tradables } \\
\hline \multirow[b]{2}{*}{ Período } & \multicolumn{2}{|c|}{ Variação Total } & \multicolumn{2}{|c|}{ Efeito Substituição } & Efeito Escala & \multirow{2}{*}{\begin{tabular}{|c} 
Efeito \\
substituição \\
$\%$
\end{tabular}} \\
\hline & $\begin{array}{l}\text { Total no } \\
\text { período }\end{array}$ & $\begin{array}{l}\text { Média } \\
\text { anual }\end{array}$ & $\begin{array}{l}\text { Total no } \\
\text { período }\end{array}$ & $\begin{array}{l}\text { Média } \\
\text { anual }\end{array}$ & $\begin{array}{l}\text { Total no Média } \\
\text { período anual }\end{array}$ & \\
\hline 0 & 6,76 & 0,75 & 8,46 & 0,94 & $-1,70 \quad-0,19$ & $125,23 \%$ \\
\hline & 4,66 & 0,93 & 5,62 & 1, & $-0,96$ & $120,52 \%$ \\
\hline $1981-97$ & 12,00 & 0,75 & 14,51 & 0,91 & $-2,53$ & $121,02 \%$ \\
\hline
\end{tabular}

Como esperado, o efeito escala ganha relevância em relação aos dados da tabela 2. Contudo, apesar de negativo sua magnitude continua restrita em comparação ao efeito substituição, enquanto que a proporção devida ao efeito escala para os anos posteriores à abertura revelou-se inferior aos valores do período anterior a tal evento. Além disso, o efeito escala continua sendo relativamente mais importante em setores non-tradable do que na manufatura, o que reforça qualitativamente as conclusões anteriores.

Nas figuras 5a e 5b reporta-se a decomposição descrita na equação (2), mas em intervalos de um ano. No que toca aos resultados para emprego relativo, podese perceber a mesma predominância do efeito substituição com sinal positivo em quase todos anos. Já o sinal do efeito escala oscila bastante na década de 80, mas na década de 90 é possível estabelecer um certo padrão: até 1993, observamse valores negativos e até certo ponto fortes, o que pode ser compatível com a hipótese de abertura; porém, nos anos posteriores, o sinal volta a ser positivo e com magnitude particularmente importante no ano de 1997.

O gráfico referente à massa salarial apresenta resultados menos claros, mas ainda com efeitos substituição positivos e de alta magnitude na maioria dos anos considerados. O efeito escala ganha mais importância, mas também muda muito de ano para ano, não sendo possível confirmar o padrão do início da década de 90 encontrado para o emprego relativo. Contudo, nos últimos anos efeitos escala positivos voltam a aparecer, destacando-se em magnitude no ano de 1997. 
Figura 5a

Efeitos escala e substituição ano a ano - emprego relativo

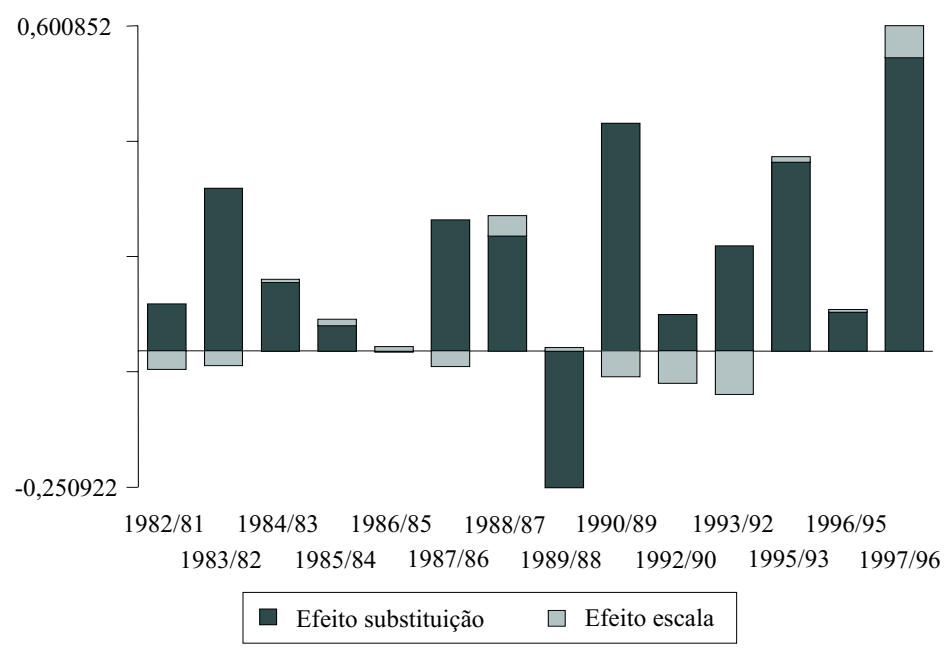

Figura 5b

Efeitos escala e substituição ano a ano - massa salarial relativa

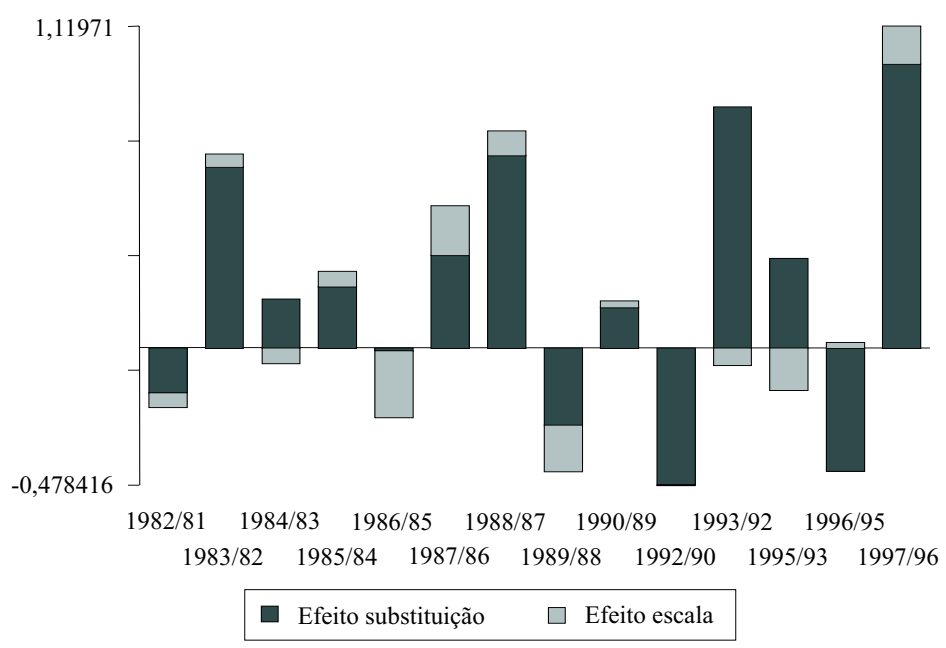


Vale ressaltar que estes resultados devem ser vistos com alguma cautela, dado que estamos utilizando setores razoavelmente agregados. A idéia é que dentro de cada indústria poderiam ocorrer movimentos de fatores das firmas mais intensivas em qualificação para as menos intensivas (ou vice-versa). A agregação esconderia tais efeitos, o que tornaria o componente intersetorial tão restrito como o observado. $^{12}$

Machin et alii (1996) realizam este exercício para Estados Unidos, Reino Unido, Dinamarca e Suécia, de 1973 a 1989, também chegando a valores expressivos para o efeito substituição. Além disso, avaliam a contribuição de cada setor para a variação do uso (massa salarial) relativo de qualificados a partir da decomposição: os mais relevantes, tanto para a variação total como para a variação intrasetorial, seriam indústria de papel, impressão e publicação, indústria de computadores e máquinas não elétricas, indústria de professional goods, sendo esses setores identificados com o uso de alta tecnologia.

Os resultados para o caso brasileiro estão nas figuras 6a e 6b. Pode-se visualizar que entre os setores mais importantes está a indústria editorial/gráfica, que também tem papel fundamental nos países antes citados. Contudo, indústrias como alimentos, vestuário e material de transporte, bastante relevantes na manufatura brasileira no período 1981-97, possuem impacto menor nesses mesmos países. É interessante notar que visualmente parece não haver correlação entre contribuição para o efeito total (e efeito substituição) sobre o uso de qualificação e intensidade fatorial em quaisquer dos períodos focalizados: observa-se contribuições fortes em indústrias de alta, média e baixa intensidade em qualificados. De fato, todas as correlações entre efeitos substituição e uso relativo de trabalhadores mais educados (não reportadas) são não significantes. ${ }^{13}$

\footnotetext{
${ }^{12} \mathrm{Na}$ verdade, este é um problema que acompanha todos os artigos que fazem uso desta metodologia, que em sua grande maioria reportam componentes intersetoriais relativamente baixos.

${ }^{13}$ Pode-se argumentar ainda que os valores baixos dos efeitos escala podem ser resultantes da dotação intermediária de qualificados por parte do Brasil, uma vez que os fatores poderiam estar se deslocando para indústrias medianamente intensivas em qualificação, isto é, efeitos escala altos e positivos para tais setores. Este também não parece ser o caso aqui, como pode ser observado nos gráficos das figuras 6a e 6b (lembrando que as indústrias estão ordenadas decrescentemente pelo emprego relativo em 1981).
} 
Figura 6a

Efeitos substituição e escala - contribuição por setor

(emprego relativo)

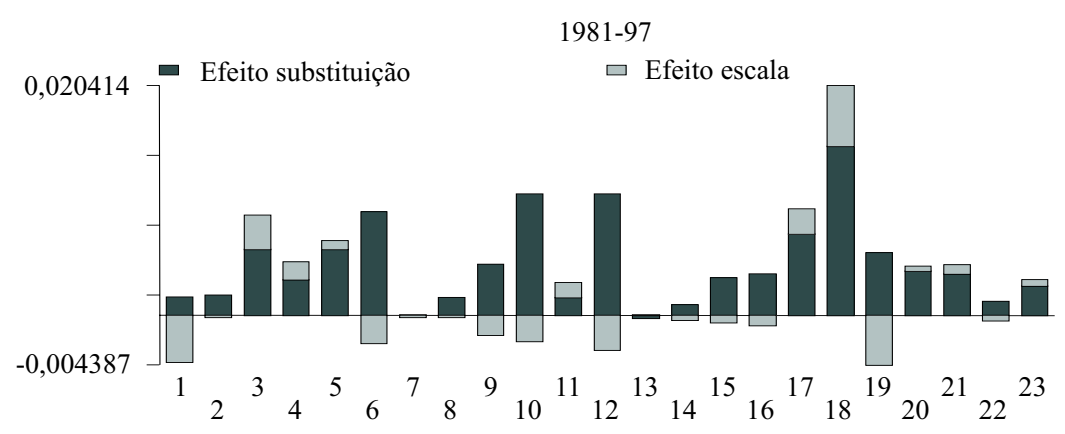

$1981-90$

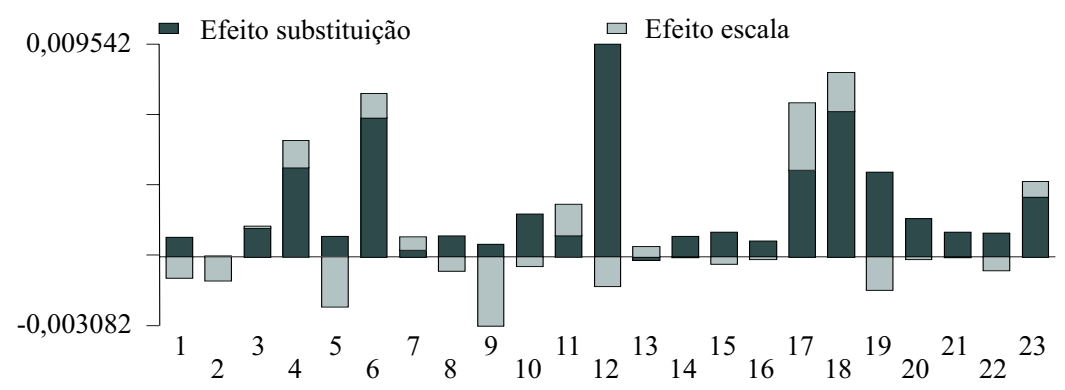

$1992-97$

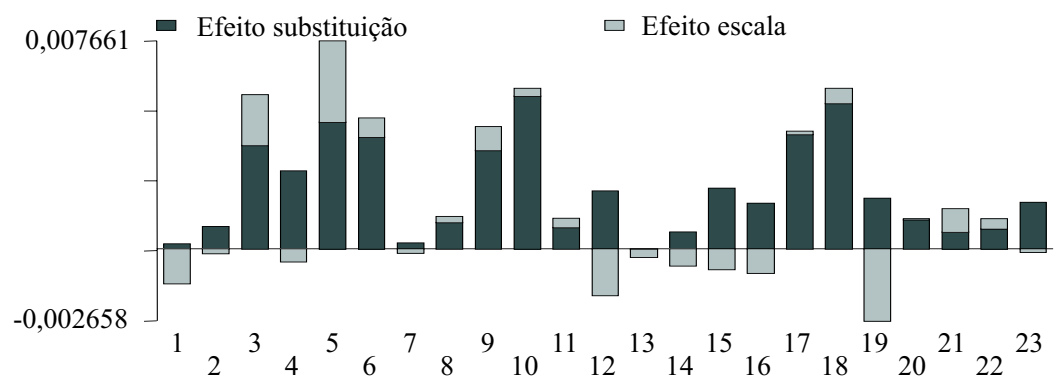

Nota: a numeração dos setores segue a da tabela 1. 
Figura $6 b$

Efeitos substituição e escala - contribuição por setor

(massa salarial relativa)

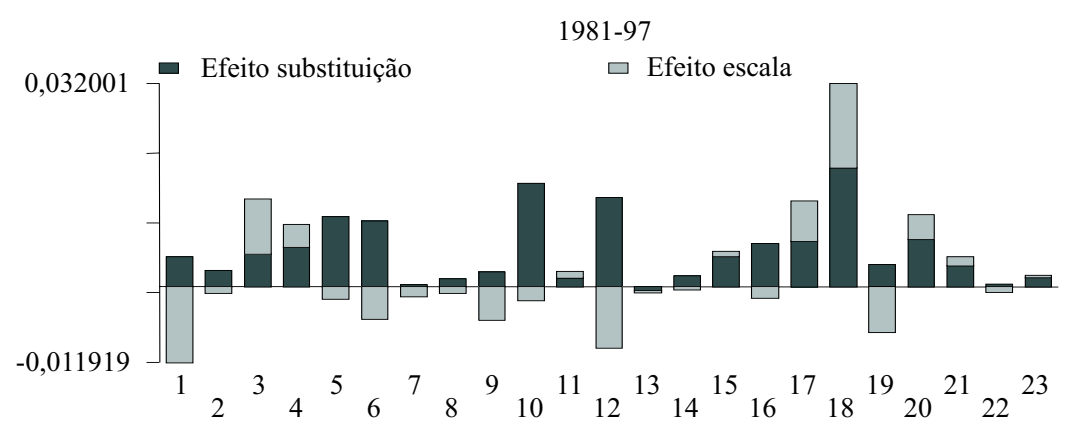

$1981-90$

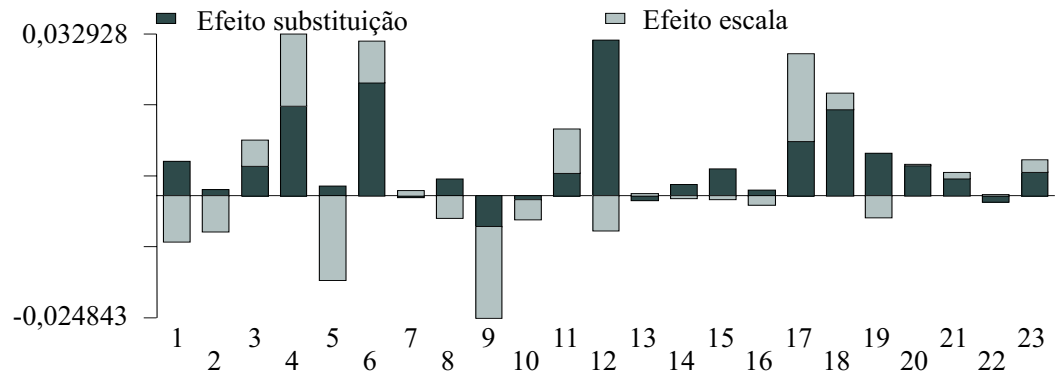

$1992-97$

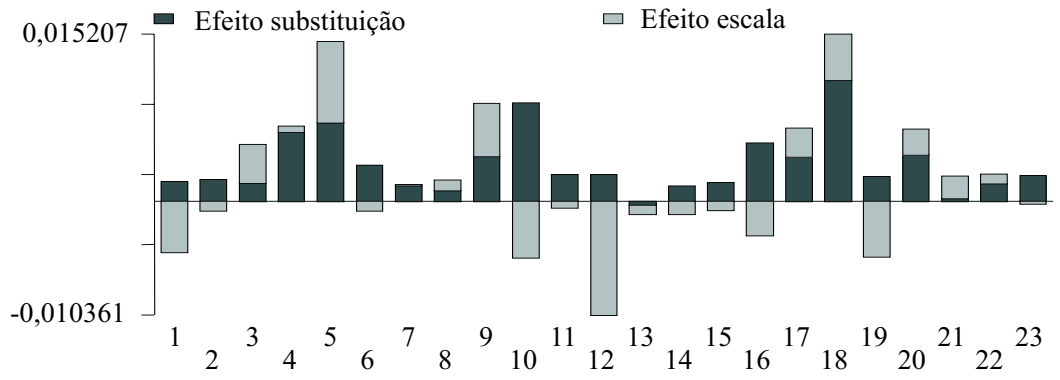

\section{Análise Econométrica}

De acordo com os resultados anteriores, parece inegável o aumento do uso de trabalho qualificado, tanto no agregado como vários setores em particular. Além disso, a maior parte desta variação deu-se de maneira intra-setorial. Esta evidência é particularmente contrária à hipótese de que o modelo de Heckscher-Ohlin seria importante para explicar tais movimentos, uma vez que se deveria observar variações na demanda relativa como resultado do movimento de fatores para setores 
com maior ou menor intensidade em qualificação, ou seja, fortes movimentos intersetorias.

Por outro lado, caso acreditemos que houve movimentos relevantes na demanda relativa por qualificação, tais fatos sinalizariam que esta demanda também seria refletida dentro dos setores, de modo que estes seriam incentivados a contratar relativamente mais trabalho qualificado.

A presente seção busca explicar esta mudança, considerando principalmente o impacto da tecnologia sobre o uso de qualificação, o que pode fornecer evidências de progresso técnico enviesado para trabalho qualificado. Além disso, enfoca-se a influência do capital físico - dentro da idéia de complementaridade entre este fator e o trabalho qualificado - nesse processo.

\subsection{Modelo econométrico}

A abordagem que aqui utilizamos segue de perto a proposta por Machin et alii (1996). Supõe-se que as firmas de cada setor $i$, a cada ano $t$, minimizem uma função custo translog $C\left(\ln w_{i t}^{S}, \ln w_{i t}^{U}, \ln K_{i t}, T E C_{i t}\right)$, em que:

$w_{i t}^{S}$ é o salário médio dos trabalhadores qualificados na indústria $i$, ano $t$;

$w_{i t}^{U}$ é o salário médio dos trabalhadores não qualificados na indústria $i$, ano $t$;

$K_{i t}$ é o estoque de capital físico da indústria $i$, ano $t$;

$T E C_{i t}$ representa a tecnologia da indústria $i$, ano $t$.

Tecnologia e capital são tratados como insumos quase fixos. Pelo lema de Shephard, chega-se a:

$$
W_{i t}=\mu_{i}+\beta_{0} \ln Y_{i t}+\beta_{1} \ln \left(w_{i t}^{S} / w_{i t}^{U}\right)+\beta_{2} \ln K_{i t}+\beta_{3} T E C_{i t}
$$

sendo que $W_{i t}$ é a parcela da massa salarial dedicada ao fator trabalho qualificado na indústria $i$, ano $t, \mu_{i}$ denota o efeito individual específico do setor $i$, invariante no tempo, e $Y_{i t}$ representa o valor da transformação industrial do setor $i$, ano t. Valores positivos para $\beta_{2}$ indicam complementaridade entre capital físico e trabalho qualificado, enquanto que $\beta_{3}>0$ significa tecnologia enviesada para qualificação. Extraindo primeiras diferenças (representadas por $\Delta$ ), e incluindo um termo de erro aleatório não autocorrelacionado $u_{i t}$ : 


$$
\Delta W_{i t}=\beta_{0} \Delta \ln Y_{i t}+\beta_{1} \Delta \ln \left(w_{i t}^{S} / w_{i t}^{U}\right)+\beta_{2} \Delta \ln K_{i t}+\beta_{3} P \& D_{i t}+\beta_{4} D_{t}+u_{i t}
$$

em que $D_{t}$ são dummies anuais, incluídas para captar choques comuns a todos os setores em determinado ano $t .{ }^{14}$ Já $P \& D_{i t}$ representa intensidade de P\&D da indústria $i$, ano $t$, que constitui uma proxy para a mudança tecnológica anual.

Os dados de capital foram gerados pelo IPEA a partir de dados de investimento da PIA. ${ }^{15}$ Esta pesquisa também é a fonte dos dados de $Y_{i t}$, obtidos porém no site do IBGE. Com relação à intensidade de $\mathrm{P} \& \mathrm{D}$, utiliza-se duas fontes. A primeira delas é de responsabilidade da Associação Nacional de Pesquisa e Desenvolvimento das Empresas Industriais (Anpei) a qual amostra cerca de 400 companhias por ano em diversos setores industriais, entre 1994 e 1998. Como a amostra de firmas é muito restrita, utilizou-se a média temporal simples dos valores de gastos em $\mathrm{P} \& \mathrm{D}$ e faturamento bruto e por setor ao longo do período amostrado, com vistas a atenuar erros de medida. A partir daí, a seguinte medida foi criada:

$$
\text { Anpei }=\frac{\text { Média dos gastos em P\&D do setor }}{\text { Média do faturamento bruto do setor }}
$$

A segunda fonte é a pesquisa Paep, censo das empresas paulistas, de responsabilidade da Fundação Seade, relativa apenas ao ano de 1996. Apesar das informações estarem restritas a São Paulo, esse Estado abriga parte bastante representativa da manufatura brasileira. O banco não contém informações sobre o montante gasto em $\mathrm{P} \& \mathrm{D}$, mas somente se a empresa realiza ou não esta atividade. Assim, a intensidade de P\&D é mensurada da seguinte forma:

$$
\text { Paep }=\frac{\text { Número de empresas envolvidas com P\&D no setor em } 1996}{\text { Número total de empresas do setor em } 1996}
$$

,É notável que em ambos os casos a intensidade de P\&D é constante ao longo dos anos, variando apenas entre indústrias. A estratégia utilizada para contornar esta dificuldade consistiu em replicar tais observações para todo o período da

\footnotetext{
${ }^{14}$ Dada a provável endogeneidade do salário relativo, Machin, Ryan \& Van Reenen sugerem este regressor poderia ser excluído de (3). Tal estratégia está baseada na hipótese de que as remunerações movem-se de maneira bastante parecida entre os setores, de modo que o efeito desta variável já estaria sendo captado pelas dummies anuais. No entanto, em nosso caso, o termo de salários relativos revelou-se bastante importante para chegarmos aos resultados que serão expostos, provavelmente sinalizando que esta não seria uma boa hipótese para o Brasil.

${ }^{15}$ Rossi e Ferreira (1999).
} 
amostra, com base no fato estilizado observado por Klette e Griliches (2000), que indica que a variável associada a P\&D é bastante estável ao longo dos anos, sendo bem explicada por um random walk. ${ }^{16}$

A compatibilização destas diferentes fontes de informação resultou em duas amostras acompanhadas entre 1989 e 1997. Na amostra 1 os dados foram agregados em 14 setores manufatureiros, sendo utilizados para as regressões com a medida de P\&D da Anpei. Já a amostra 2 é composta por 12 setores, organizados de acordo com a base da Paep. ${ }^{17,18}$

A estimação se dá por mínimos quadrados ponderados, sendo a proporção da massa salarial total dos setores alocada no setor $i$, ano $t$, a ponderação utilizada na equação (3). Consideram-se as duas amostras não só durante o período 1989-97, mas também no subperíodo 1994-97, caracterizado por uma maior estabilidade econômica, retomada dos investimentos e entrada de capital externo quando comparado aos anos anteriores.

Apesar de não decorrer diretamente da teoria, estima-se também a equação (3) com o emprego relativo de qualificados em lugar da massa salarial relativa, o que atenuaria o provável problema de endogeneidade do salário relativo. As interpretações dos coeficientes $\beta_{2}$ e $\beta_{3}$ não mudam. Neste caso, os pesos são dados pela proporção do número total de trabalhadores alocada no setor $i$.

Nas colunas (1) e (2) das tabelas 4a e 4b são apresentados os resultados da regressão (3) para o período 1989-97 e para o subperíodo 1994-97. Entre 1989 e 1997 a relação entre a variável tecnológica e as medidas de uso de qualificação é muito fraca, dada a baixa significância dos coeficientes associados à intensidade de P\&D. Contudo, entre 1994 e 1997 a evidência de viés tecnológico para o trabalho qualificado aparece com mais força, sendo que $P \mathscr{E} D$ é positivamente correlacionado tanto com o emprego com a massa salarial relativa para as duas medidas desta variável consideradas.

Isto pode sugerir que o período 1994-97 poderia ter favorecido o efeito da tecnologia, já que é marcado por uma maior estabilidade, retomada dos investimentos e maior entrada de capital externo, quando comparado aos anos de recessão imediatamente anteriores. Porém é preciso levar em conta que os dados de intensidade

\footnotetext{
${ }^{16}$ Perdomo et alii (2001) chegam a resultados parecidos para o Brasil, a partir dos dados de firmas da Anpei.

${ }^{17}$ Os dados de emprego e massa salarial foram intrapolados para 1991 e 1994, por conta da ausência de PNADs em tais anos. O mesmo foi feito com respeito aos dados de valor da transformação industrial de 1991, mas a intrapolação se deu no log - já que esta variável é utilizada no log nas regressões.

${ }^{18}$ Para uma descrição mais pormenorizada destas compatibilizações ver Rodrigues (2001, p.86$89)$.
} 
de $\mathrm{P} \& \mathrm{D}$ utilizados dizem respeito justamente ao período em que seu coeficiente mostrou-se altamente significante: os dados da Anpei foram construídos a partir da média das observações entre 1994 e 1998 e os dados da Paep são referentes ao ano de 1996. A tecnologia poderia até ser enviesada nos anos anteriores, mas a distância temporal da medida estaria escondendo uma correlação mais alta.

Tabela $4 \mathrm{a}$

Resultados da estimação de (3) Variável Dependente: $\Delta$ (Emprego relativo)

\begin{tabular}{|c|c|c|c|c|c|c|}
\hline \multicolumn{7}{|c|}{ Intensidade de P\&D = Anpei } \\
\hline & $(1)$ & $(2)$ & $(3)$ & $(4)$ & $(5)$ & $(6)$ \\
\hline \multirow[t]{2}{*}{$P \& D$} & 0,200 & $0,781^{*}$ & 1,122 & $2,619^{* *}$ & $2,440^{* *}$ & $2,123^{* *}$ \\
\hline & $(0,511)$ & $(0,073)$ & $(0,125)$ & $(0,033)$ & $(0,039)$ & $(0,056)$ \\
\hline \multirow[t]{2}{*}{$\Delta \ln K$} & $0,066^{* *}$ & 0,013 & $0,096^{* *}$ & 0,137 & 0,125 & 0,093 \\
\hline & $(0,049)$ & $(0,900)$ & $(0,020)$ & $(0,339)$ & $(0,369)$ & $(0,485)$ \\
\hline \multirow[t]{2}{*}{$\Delta \ln Y$} & $-0,007$ & 0,002 & $-0,004$ & 0,007 & 0,007 & 0,008 \\
\hline & $(0,583)$ & $(0,907)$ & $(0,751)$ & $(0,681)$ & $(0,696)$ & $(0,645)$ \\
\hline \multirow[t]{2}{*}{$\Delta \ln \left(w^{S} / w^{U}\right)$} & $-0,003$ & $0,040 * *$ & $-0,002$ & $0,061^{* *}$ & $0,059 * *$ & $0,068^{*}$ \\
\hline & $(0,780)$ & $(0,030)$ & $(0,884)$ & $(0,016)$ & $(0,016)$ & $(0,075)$ \\
\hline \multirow{3}{*}{$\begin{array}{l}\text { Instrumentos para } \\
\qquad P \& D\end{array}$} & - & - & $R \& D_{t-1}$ & $R \& D_{t-1}$ & $R \& D_{t-1}$ & $R \& D_{t-1}$ \\
\hline & & & & & $R \& D_{t-2}$ & $R \& D_{t-2}$ \\
\hline & & & & & $R \& D_{t-3}$ & $R \& D_{t-3}$ \\
\hline \multirow{4}{*}{$\begin{array}{c}\text { Instrumentos para } \\
\Delta \ln \left(w^{S} / w^{U}\right) \\
\text { Período } \\
N\end{array}$} & - & - & - & - & - & $\Delta \ln \left(w^{S} / w^{U}\right)_{t-1}$ \\
\hline & & & & & & $\Delta \ln \left(w^{S} / w^{U}\right)_{t-2}$ \\
\hline & $1989-97$ & 1994-97 & 1989-97 & 1994-97 & 1994-97 & 1994-97 \\
\hline & 126 & 56 & 126 & 56 & 56 & 56 \\
\hline \multicolumn{7}{|c|}{ Intensidade de P\&D = Paep } \\
\hline & (1) & $(2)$ & $(3)$ & $(4)$ & $(5)$ & (6) \\
\hline \multirow{2}{*}{$P \& D$} & $0,27^{* *}$ & $0,059^{* *}$ & 0,052 & $0,100^{* *}$ & $0,107^{* *}$ & $0,104^{* *}$ \\
\hline & $(0,099)$ & $(0,010)$ & $(0,112)$ & $(0,028)$ & $(0,020)$ & $(0,026)$ \\
\hline \multirow[t]{2}{*}{$\Delta \ln K$} & $0,095 * *$ & $-0,015$ & $0,117^{* *}$ & 0,030 & 0,038 & 0,030 \\
\hline & $(0,037)$ & $(0,914)$ & $(0,026)$ & $(0,844)$ & $(0,808)$ & $(0,846)$ \\
\hline \multirow[t]{2}{*}{$\Delta \ln Y$} & $-0,014$ & $-0,017$ & $-0,016$ & $-0,023$ & $-0,024$ & $-0,022$ \\
\hline & $(0,340)$ & $(0,373)$ & $(0,287)$ & $(0,267)$ & $(0,253)$ & $(0,306)$ \\
\hline \multirow[t]{2}{*}{$\Delta \ln \left(w^{S} / w^{U}\right)$} & $-0,002$ & $0,036^{* *}$ & $-0,002$ & $0,040^{* *}$ & $0,041^{* *}$ & $0,057^{*}$ \\
\hline & $(0,872)$ & $(0,063)$ & $(0,866)$ & $(0,044)$ & $(0,042)$ & $(0,102)$ \\
\hline \multirow{3}{*}{$\begin{array}{l}\text { Instrumentos para } \\
\qquad P \& D\end{array}$} & - & - & $R \& D_{t-1}$ & $R \& D_{t-1}$ & $R \& D_{t-1}$ & $R \& D_{t-1}$ \\
\hline & & & & & $R \& D_{t-2}$ & $R \& D_{t-2}$ \\
\hline & & & & & $R \& D_{t-3}$ & $R \& D_{t-3}$ \\
\hline \multirow{4}{*}{$\begin{array}{c}\text { Instrumentos para } \\
\Delta \ln \left(w^{S} / w^{U}\right) \\
\text { Período } \\
N \\
\end{array}$} & - & - & - & - & - & $\Delta \ln \left(w^{S} / w^{U}\right)_{t-1}$ \\
\hline & & & & & & $\Delta \ln \left(w^{S} / w^{U}\right)_{t-2}$ \\
\hline & $1989-97$ & 1994-97 & 1989-97 & 1994-97 & 1994-97 & $1994-97$ \\
\hline & 108 & 48 & 108 & 48 & 48 & 48 \\
\hline
\end{tabular}

Nota: Valores entre parênteses são p-values. Todas as regressões incluem dummies anuais.

*significante a $10 \%, * *$ significante a $5 \%$ 
Tabela $4 \mathrm{~b}$

Resultados da estimação de (3) Variável Dependente: $\Delta$ (massa salarial relativa)

\begin{tabular}{|c|c|c|c|c|c|c|}
\hline \multicolumn{7}{|c|}{ Intensidade de $\mathrm{P} \& \mathrm{D}=$ Anpei } \\
\hline & $(1)$ & $(2)$ & $(3)$ & (4) & (5) & (6) \\
\hline \multirow[t]{2}{*}{$P \& D$} & 0,201 & $1,082^{*}$ & 0,842 & $2,116^{*}$ & $1,976^{*}$ & $1,714^{*}$ \\
\hline & $(0,629)$ & $(0,056)$ & $(0,275)$ & $(0,067)$ & $(0,081)$ & $(0,099)$ \\
\hline \multirow[t]{2}{*}{$\Delta \ln K$} & $0,099^{*}$ & $-0,020$ & $0,104^{* *}$ & $-0,028$ & $-0,027$ & $-0,025$ \\
\hline & $(0,054)$ & $(0,883)$ & $(0,046)$ & $(0,846)$ & $(0,850)$ & $(0,857)$ \\
\hline \multirow[t]{2}{*}{$\Delta \ln Y$} & $-0,019$ & 0,004 & $-0,018$ & 0,004 & 0,004 & 0,003 \\
\hline & $(0,293)$ & $(0,849)$ & $(0,336)$ & $(0,851)$ & $(0,850)$ & $(0,869)$ \\
\hline$\Delta \ln \left(w^{S} / w^{U}\right)$ & $\begin{array}{c}0,222 * * \\
(0,000)\end{array}$ & $\begin{array}{c}0,284^{* *} \\
(0,000)\end{array}$ & $\begin{array}{c}0,221 * * \\
(0,000)\end{array}$ & $\begin{array}{c}0,295^{* *} \\
(0,000)\end{array}$ & $\begin{array}{c}0,293^{* *} \\
(0,000)\end{array}$ & $0,287^{* *}$ \\
\hline \multirow{3}{*}{$\begin{array}{l}\text { Instrumentos para } \\
P \& D\end{array}$} & - & - & $R \& D_{t-1}$ & $R \& D_{t-1}$ & $R \& D_{t-1}$ & $R \& D_{t-1}$ \\
\hline & & & & & $R \& D_{t-2}$ & $R \& D_{t-2}$ \\
\hline & & & & & $R \& D_{t-3}$ & $R \& D_{t-3}$ \\
\hline \multirow{4}{*}{$\begin{array}{c}\text { Instrumentos para } \\
\Delta \ln \left(w^{S} / w^{U}\right) \\
\text { Período } \\
N \\
\end{array}$} & - & - & - & - & - & $\Delta \ln \left(w^{S} / w^{U}\right)_{t-1}$ \\
\hline & & & & & & $\Delta \ln \left(w^{S} / w^{U}\right)_{t-2}$ \\
\hline & $1989-97$ & $1994-97$ & $1989-97$ & 1994-97 & $1994-97$ & 1994-97 \\
\hline & 126 & 56 & 126 & 56 & 56 & 56 \\
\hline \multicolumn{7}{|c|}{ Intensidade de $\mathrm{P} \& \mathrm{D}=$ Paep } \\
\hline & (1) & $(2)$ & $(3)$ & (4) & $(5)$ & $(6)$ \\
\hline \multirow[t]{2}{*}{$P \& D$} & 0,29 & $0,070^{* *}$ & 0,038 & $0,084^{*}$ & $0,099^{* *}$ & $0,090^{*}$ \\
\hline & $(0,132)$ & $(0,008)$ & $(0,258)$ & $(0,080)$ & $(0,041)$ & $(0,053)$ \\
\hline \multirow[t]{2}{*}{$\Delta \ln K$} & $0,119^{*}$ & 0,019 & $0,125^{* *}$ & 0,017 & 0,015 & 0,017 \\
\hline & $(0,051)$ & $(0,906)$ & $(0,050)$ & $(0,917)$ & $(0,930)$ & $(0,920)$ \\
\hline \multirow[t]{2}{*}{$\Delta \ln Y$} & $-0,028$ & $-0,016$ & $-0,028$ & $-0,017$ & $-0,018$ & $-0,018$ \\
\hline & $(0,203)$ & $(0,513)$ & $(0,201)$ & $(0,486)$ & $(0,456)$ & $(0,477)$ \\
\hline \multirow[t]{2}{*}{$\Delta \ln \left(w^{S} / w^{U}\right)$} & $-0,221 * *$ & $0,283^{* *}$ & $0,221^{* *}$ & $0,285^{* *}$ & $0,289 * *$ & $0,287^{* *}$ \\
\hline & $(0,000)$ & $(0,000)$ & $(0,000)$ & $(0,000)$ & $(0,000)$ & $(0,000)$ \\
\hline \multirow{3}{*}{$\begin{array}{l}\text { Instrumentos para } \\
\qquad \& \& D\end{array}$} & - & - & $R \& D_{t-1}$ & $R \& D_{t-1}$ & $R \& D_{t-1}$ & $R \& D_{t-1}$ \\
\hline & & & & & $R \& D_{t-2}$ & $R \& D_{t-2}$ \\
\hline & & & & & $R \& D_{t-3}$ & $R \& D_{t-3}$ \\
\hline \multirow{4}{*}{$\begin{array}{c}\text { Instrumentos para } \\
\Delta \ln \left(w^{S} / w^{U}\right) \\
\text { Período } \\
N\end{array}$} & - & - & - & - & - & $\Delta \ln \left(w^{S} / w^{U}\right)_{t-1}$ \\
\hline & & & & & & $\Delta \ln \left(w^{S} / w^{U}\right)_{t-2}$ \\
\hline & $1989-97$ & $1994-97$ & $1989-97$ & 1994-97 & $1994-97$ & $1994-97$ \\
\hline & 108 & 48 & 108 & 48 & 48 & 48 \\
\hline
\end{tabular}

Nota: Valores entre parênteses são p-values. Todas as regressões incluem dummies anuais.

*significante a $10 \%, * *$ significante a $5 \%$

Outro fato interessante a ser ressaltado está na alta correlação do capital físico tanto com emprego como com massa salarial relativa, o que traz indícios de complementaridade entre este fator e o trabalho qualificado no período 1989-97. Este efeito também pode estar refletindo impactos da tecnologia, na medida que o capital físico (principalmente em suas gerações mais novas) passa a incorporar parte 
da mudança tecnológica. A significância estatística, entretanto, não é encontrada no subperíodo 1994-97.

Surpreendentemente, no período mais recente o coeficiente dos salários relativos aparece com sinal positivo e significante quando a variável dependente é o emprego relativo, o que pode sugerir que algum outro componente importante na demanda relativa por qualificação não esteja especificado no modelo. Entretanto, deve-se levar em conta que, mesmo na regressão com emprego relativo, possivelmente haverá problemas de endogeneidade, dado que preços (salários) e quantidades (emprego) são determinados simultaneamente.

\subsection{Transferência de tecnologia}

Talvez a principal crítica à evidência aqui apresentada (notadamente a de complementaridade entre tecnologia e qualificação para 1994-97) esteja na qualidade discutível das proxies tecnológicas utilizadas. Estudos para países desenvolvidos que seguem esta mesma metodologia fazem uso de dados de P\&D bem mais precisos que os nossos, dispondo do montante gasto nesta atividade por setor em diversos anos.

Além disso, pode-se argumentar que, em nosso caso, a intensidade de P\&D seria uma medida pouco adequada para captar o estado tecnológico de cada setor, na medida em que o Brasil é muito mais um importador do que um produtor de tecnologia. Em suma, é provável que esta variável apresente sérios erros de medida.

Neste sentido, estimamos este mesmo modelo, mas utilizando dados de intensidade de P\&D dos Estados Unidos para instrumentalizar a variável brasileira. A justificativa para tal estratégia baseia-se na hipótese de transferência tecnológica, sendo que parte significativa da tecnologia utilizada pelas firmas brasileiras seria importada dos países desenvolvidos (em particular dos Estados Unidos). A influência, assim, da tecnologia externa sobre o mercado de trabalho brasileiro seria indireta, dada por meio da tecnologia brasileira.

A intensidade de $\mathrm{P} \& \mathrm{D}$ dos Estados Unidos (denotada por $R \& D$ ) é representada pela razão entre os gastos em $\mathrm{P} \& \mathrm{D}$ e o valor adicionado de cada setor, ano. Tais dados provêm da OCDE e são os mesmos do artigo de Machin et alii (1998), sendo compatibilizados de acordo com nossas duas amostras. ${ }^{19}$ Esta variável mostrou-se

\footnotetext{
${ }^{19}$ Alguns setores no banco de dados americano revelaram-se bastante agregados quando comparados a nossas duas amostras. Para não restringir demais o número de observações, os valores de $R \& D$ foram replicados para determinados setores. Por exemplo, a indústria têxtil e a indústria de vestuário/calçados receberam o mesmo valor de $R \& D$, posto que estavam agregadas nos dados
} 
positivamente correlacionada com sua equivalente brasileira, sendo tais correlações relativamente altas, apesar de sua baixa significância (provavelmente dada pelo pequeno número de observações em cada cross-section). Isto pode ser visto na tabela 5, a qual traz algumas correlações entre a variável brasileira e a americana (tanto no nível como em algumas defasagens) para o ano de 1996 (resultados semelhantes para demais anos). ${ }^{20}$

Tabela 5

Correlações

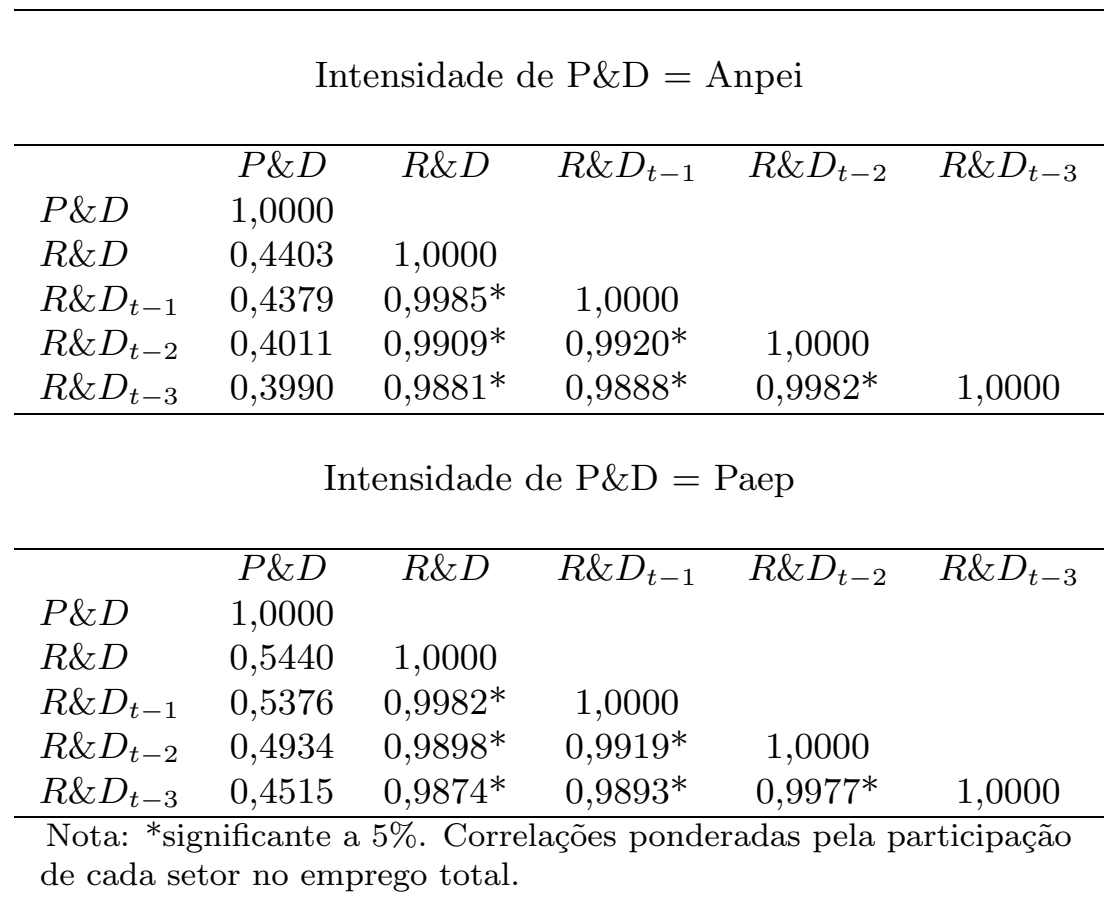

Os resultados da estimação da equação (3) via variáveis instrumentais encontram-se nas tabelas $4 \mathrm{a}$ e $4 \mathrm{~b}$. Nas colunas (3) e (4) utilizamos $R \& D$ defasado em um período como instrumento para $P \& D$. Qualitativamente os resultados mudam pouco: a intensidade de $\mathrm{P} \& \mathrm{D}$ continua positiva e significativamente correlacionada com o uso relativo de trabalhadores qualificados apenas entre 1994 e 1997 para ambas as amostras, o que reforça a evidência de viés tecnológico neste período.

Todavia, o que chama mais a atenção é a mudança de magnitude dos coeficientes da variável $P \& D$ com relação ao caso em que os instrumentos não foram aplicados, sobretudo para o período mais recente. Este fato pode sinalizar que

dos Estados Unidos.

${ }^{20}$ Além disso, as defasagens de $R \& D$ mostraram-se altamente correlacionadas entre si, o que está de acordo com a idéia de que esta variável é bastante estável no tempo. 
o instrumento é realmente relevante neste caso, sugerindo que a transferência de tecnologia teria papel importante sobre o uso relativo de qualificação nos últimos anos. A inclusão de mais duas defasagens de $R \& D$ na matriz de instrumentos pouco altera estes resultados - como exposto na coluna (5) -, o que reforça nossa evidência.

Por fim, estimamos o mesmo modelo, mas tratando o problema de endogeneidade da variável referente a salários relativos. Para tanto, utilizamos as duas primeiras defasagens dessa variável $-\Delta \ln \left(w^{S} / w^{U}\right)_{t-1}$ e $\Delta \ln \left(w^{S} / w^{U}\right)_{t-2}$ - para instrumentalizá-la. Os resultados, reportados na coluna (6) das tabelas 4a e 4b, novamente mudam muito pouco. A variável tecnológica permanece significante a 10\% para o período 1994-97. Além disso, nas regressões em que o emprego relativo é a variável dependente, pode-se observar uma perda de significância de $\Delta \ln \left(w^{S} / w^{U}\right)$, apesar de ainda apresentar sinal positivo. ${ }^{21}$

Os mesmos exercícios das tabelas $4 \mathrm{a}$ e $4 \mathrm{~b}$ foram refeitos utilizando outras definições de trabalho qualificado dentro da amostra da PNAD. Os resultados estão expostos no anexo.

\section{Conclusão}

Ao longo deste artigo, constatou-se que a utilização de trabalho qualificado (indivíduos com 11 ou mais anos de estudo), tanto na proporção de trabalhadores empregados como na massa salarial dedicada a tal fator, apresentou significativo aumento nas décadas de 80 e 90. Esta tendência não ficou restrita ao agregado, mas esteve presente em diversos níveis mais desagregados da atividade econômica.

Naturalmente, questiona-se se estes movimentos têm origem no grande aumento da oferta de qualificados ocorrido ao longo dos últimos anos, ou se uma maior demanda por trabalho qualificado teria também relevância. Argumentamos que choques na demanda relativa de qualificação teriam sua importância na determinação do emprego relativo de tal fator. Esta variável e a de massa salarial relativa andam juntas tanto no agregado como em diversos setores em particular. Tal comportamento conjunto só seria compatível com choques unicamente do lado da oferta se todos os setores observados apresentassem elasticidade-substituição entre trabalho qualificado e não qualificado maior que 1.

Se esta interpretação estiver correta, o que teria levado esta demanda a aumentar? A decomposição da variação do emprego relativo e da massa salarial nos

${ }^{21} \mathrm{~A}$ variável referente ao capital físico permanece positiva e significante a $10 \%$ para o período 1989-97 (resultados não reportados) mesmo após a inclusão dos instrumentos para $P \& D$ e $\Delta \ln \left(w^{S} / w^{U}\right)$. 
componentes intersetorial e intrasetorial (com este último sendo muito mais importante), dá uma indicação de que a abertura comercial, via modelo de HeckscherOhlin, não parece ser uma boa explicação. Outros elementos, como progresso técnico enviesado para trabalho qualificado, complementaridade entre qualificação e capital físico poderiam ser respostas mais compatíveis com esta evidência.

Neste sentido, procedemos à estimação de um modelo econométrico que realiza a ligação entre o uso de qualificação, tecnologia e capital físico. Tanto o emprego relativo como a massa salarial relativa revelaram-se positivamente relacionadas com a variável tecnológica para o subperíodo 1994-97, o que parece estar influenciando seu movimento conjunto. É possível ainda que tal correlação estenda-se para todo o período 1989-97, já que as proxies de tecnologia dizem respeito ao subperíodo considerado.

As estimativas ainda mostraram relação positiva entre estoque de capital e uso de qualificação entre 1989 e 1997, o que pode estar refletindo complementaridade entre capital físico e trabalho qualificado. Note-se que tal evidência também pode estar associada aos impactos da tecnologia, uma vez que esta pode estar sendo incorporada aos bens de capital, sobretudo em suas gerações mais recentes.

A conexão entre progresso técnico e uso de qualificação é também verificada para diversas outras economias, principalmente as mais desenvolvidas. Berman et alii (1998) argumentam que este tipo de tecnologia seria comum a uma série de países da OCDE. Berman e Machin (2000) encontram evidências de que esta tecnologia enviesada estaria propagando-se para países em desenvolvimento, trazendo impactos sobre os mercados de trabalho também destes países. Os resultados por nós encontrados na estimação via variáveis instrumentais apontam nesta mesma direção, podendo dar uma indicação de como os fenômenos ocorridos no Brasil estariam relacionados às mudanças tecnológicas originárias em economias desenvolvidas.

Assim, mesmo que os impactos da liberalização sobre o mercado de trabalho sejam limitados - conforme a evidência por nós apresentada tendo como pano de fundo o modelo de Heckscher-Ohlin - é possível que este processo produza tais efeitos de maneira indireta, na medida em que facilita a absorção de tecnologia enviesada para o trabalho qualificado oriunda de países desenvolvidos. 


\section{Referências}

Arbache, J. S. (2000). Os efeitos da globalização nos salários e o caso do Brasil. Economia, 1(1):59-92.

Arbache, J. S. \& Corseuil, C. H. (2000). Liberalização comercial e estrutura de emprego e salários. Anais do XXVIII Encontro Nacional de Economia, Anpec.

Autor, D. H., Katz, L. F., \& Krueger, A. B. (1998). Computing inequality: Have computers changed the labor markets? Quarterly Journal of Economics, 113:1169-1213.

Berman, E., Bound, J., \& Griliches, Z. (1994). Changes in the demand for skilled labor within U.S. manufacturing: Evidence from the annual survey of manufactures. Quarterly Journal of Economics, 109:367-397.

Berman, E., Bound, J., \& Machin, S. (1998). Implications of skill-biased technological change: International evidence. Quarterly Journal of Economics, 113:1245-1279.

Berman, E. \& Machin, S. (2000). Skill-biased technology transfer: Evidence of factor biased technological change in developing countries. mimeog.

Burtless, G. (1995). International trade and the rise in earnings inequality. Journal of Economic Literature, XXXIII(2):800-816.

Chennells, L. \& Van Reenen, J. (1999). Has technology hurt less skilled workers? an econometric survey of the effects of technical change on the structure of pay and jobs. IFS Working Paper Series, $n^{o}$ W99/27.

Desjonqueres, T., Machin, S., \& Van Reenen, J. (1999). Another nail in the coffin? or can the trade based explanation of changing skill structure be resurrected? Scandinavian Journal of Economics, 101(4):533-554.

Fernandes, R. \& Menezes-Filho, N. (2000). A evolução da desigualdade no Brasil metropolitano entre 1983 e 1997. Estudos Econômicos, 30(4):549-569.

Freeman, R. B. (1995). Are your wages set in beijing? Journal of Economic Perspectives, 9(3):15-32.

Green, F., Dickerson, A., \& Arbache, J. S. (2000). A picture of wage inequality and the allocation of labour through a period of trade liberalisation: The case of Brazil. Mimeog., University of Kent at Canterbury. 
Johnson, G., Stafford, F., Ashenfelter, O., \& Card, D. (1999). The labor market implications of international trade. Handbook of Labor Economics, 3:2215-2288.

Jones, R. W. (1965). The structure of simple general equilibrium models. Journal of Political Economy, 73:557-572.

Klette, T. J. \& Griliches, Z. (2000). Empirical patterns of firm growth and r\&d investment: A quality ladder model interpretation. Economic Journal, 110:363367.

Krugman, P. (1995). Technology, trade, and factor prices. NBER Working Paper Series, $\mathrm{n}^{\mathrm{O}} 5355$.

Leamer, E. E. (1994). Trade, wages and revolving door ideas. NBER Working Paper Series, $\mathrm{n}^{\circ} 4716$.

Machado, A. F. \& Moreira, M. M. (2000). Os impactos da abertura comercial sobre a remuneração relativa do trabalho no Brasil. Anais do XXVIII Encontro Nacional de Economia, Anpec.

Machin, S., Ryan, A., \& Van Reenen, J. (1996). Technology and change in skill structure: Evidence from an international panel of industries. IFS Working Paper Series, $\mathrm{n}^{o} \mathrm{~W} 96 / 6$.

Machin, S., Ryan, A., \& Van Reenen, J. (1998). Technology and changes in skill structure: Evidence from seven OECD countries. Quarterly Journal of Economics, 113:1215-1244.

Perdomo, J., Menezes-Filho, N., \& Sbragia, R. (2001). Determinantes de p\&d para firmas brasileiras: Uma análise de painel. Texto para Discussão n ${ }^{o} 13 / 2001$, IPE/USP.

Robbins, D. J. (1996). HOS hits facts: Facts win; evidence on trade and wages in the developing world. Development Discussion Papers, $n^{o}$ 557, Harvard Institute for International Development.

Rodrigues, M. J. (2001). Abertura, tecnologia e qualificação. Dissertação de Mestrado. São Paulo: IPE/USP.[http://www.teses.usp.br/teses/disponiveis/12 /12138/tde-08102001-200721/publico/Defesa.pdf.

Rossi, J. L., J. \& Ferreira, P. C. (1999). Evolução da produtividade industrial brasileira e abertura comercial. Texto para Discussão. IPEA, n ${ }^{o} 651$. 
Wood, A. (1994). North-South Trade, Employment and Inequality: Changing Fortunes in a Skill-Driven World. Clarendon, Oxford.

Wood, A. (1997). Openness and wage inequality in developing countries: The Latin American challenge to East Asian conventional wisdom. The World Bank Economic Review, 11(1):33-57. 


\section{Anexo}

\section{Outras Definições de Qualificação ${ }^{22}$}

Até o momento, classificamos como qualificados os indivíduos com 11 ou mais anos de estudo, o equivalente ao segundo grau completo. Este corte é de fato arbitrário, mas outras tentativas foram também feitas.

Por exemplo, na tabela A.1 no anexo estão os resultados da estimação da equação (3), em que os trabalhadores com 12 ou mais anos de estudo (com alguma passagem pelo ensino universitário) são considerados qualificados. Somente as regressões referentes à variação do emprego relativo são reportadas, dado que os resultados para variação da massa salarial relativa são qualitativamente semelhantes, sobretudo para as variáveis de maior interesse (capital e tecnologia).

Neste caso, as evidências de complementaridade entre capital e qualificação para 1989-97 e entre tecnologia e qualificação para 1994-97 desaparecem, dada a baixa significância dos coeficientes estimados; em certos casos, observa-se ainda reversão de sinal dos coeficientes. Todavia, a proporção de trabalhadores com mais de 11 anos de estudo nas amostras da PNAD é muito baixa, o que contribui para o aparecimento de valores muito instáveis para a variável dependente, principalmente para setores mais desagregados. Tal característica poderia estar causando a falta de significância observada.

Alternativamente, consideramos trabalhadores com 8 ou mais anos de estudo como qualificados (equivalente ao primeiro grau completo), sendo que os resultados encontram-se na tabela A.2 no anexo. Apesar de positivo, o impacto da tecnologia no uso relativo de qualificados mostrou-se limitado neste caso, na medida em que os coeficientes de $P \mathscr{E} D$ são não significativos a $10 \mathrm{em}$ sua grande maioria.

Entretanto, a evidência de complementaridade entre qualificação e capital físico (para 1989-94) é bastante forte neste caso, sendo robusta à inclusão dos instrumentos para tecnologia e salários relativos (resultados não reportados). Além disso, quando se compara as tabelas 4 a e A.2, verifica-se que os coeficientes de $\Delta \ln K$ são maiores e mais significantes nessa última. Em outras palavras, quando consideramos qualificados os indivíduos com 8 ou mais anos de estudo, o impacto do capital físico parece ser mais forte comparado ao encontrado sob a definição de qualificado aplicada anteriormente (11 ou mais anos de estudo). ${ }^{23}$

\footnotetext{
${ }^{22}$ Agradecemos a um parecerista anônimo pelas sugestões referentes a este apêndice.

${ }^{23}$ Este padrão pode ser visualizado também em várias outras regressões não reportadas no texto.
} 
Tabela A.1

Resultados da estimação de (3) Variável Dependente: $\Delta$ (Emprego relativo)

Qualificados $=$ indivíduos com 12 ou mais anos de estudo

\begin{tabular}{|c|c|c|c|c|c|c|}
\hline \multicolumn{7}{|c|}{ Intensidade de $\mathrm{P} \& \mathrm{D}=$ Anpei } \\
\hline & $(1)$ & $(2)$ & $(3)$ & $(4)$ & $(5)$ & $(6)$ \\
\hline \multirow[t]{2}{*}{$P \& D$} & 0,140 & 0,202 & 0,379 & 0,428 & 0,246 & 0,349 \\
\hline & $(0,413)$ & $(0,400)$ & $(0,340)$ & $(0,431)$ & $(0,645)$ & $(0,547)$ \\
\hline \multirow[t]{2}{*}{$\Delta \ln K$} & 0,027 & 0,002 & 0,035 & 0,017 & 0,005 & $-0,027$ \\
\hline & $(0,151)$ & $(0,971)$ & $(0,118)$ & $(0,805)$ & $(0,941)$ & $(0,724)$ \\
\hline \multirow[t]{2}{*}{$\Delta \ln Y$} & $0,012^{*}$ & $0,016^{*}$ & $0,012^{*}$ & $0,016^{*}$ & $0,016^{*}$ & $0,017^{*}$ \\
\hline & $(0,088)$ & $(0,060)$ & $(0,078)$ & $(0,059)$ & $(0,060)$ & $(0,063)$ \\
\hline \multirow{2}{*}{$\Delta \ln \left(w^{S} / w^{U}\right)$} & 0,000 & $0,011^{*}$ & 0,000 & $0,012^{*}$ & $0,011^{*}$ & $0,027^{*}$ \\
\hline & $(0,984)$ & $(0,069)$ & $(0,941)$ & $(0,065)$ & $(0,083)$ & $(0,068)$ \\
\hline \multirow{3}{*}{$\begin{array}{c}\text { Instrumentos para } \\
P \& D\end{array}$} & - & - & $R \& D_{t-1}$ & $R \& D_{t-1}$ & $R \& D_{t-1}$ & $R \& D_{t-1}$ \\
\hline & & & & & $R \& D_{t-2}$ & $R \& D_{t-2}$ \\
\hline & & & & & $R \& D_{t-3}$ & $R \& D_{t-3}$ \\
\hline Instrumentos para & - & - & - & - & - & $\begin{array}{l}\Delta \ln \left(w^{S} / w^{U}\right)_{t-1} \\
\Delta \ln \left(w^{S} / w^{U}\right)_{t-2}\end{array}$ \\
\hline Período & 1989-97 & 1994-97 & 1989-97 & 1994-97 & 1994-97 & 1994-97 \\
\hline \multirow[t]{3}{*}{$N$} & 126 & 56 & 126 & 56 & 56 & 56 \\
\hline & \multicolumn{5}{|c|}{ Intensidade de $\mathrm{P} \& \mathrm{D}=$ Paep } & \\
\hline & (1) & $(2)$ & $(3)$ & (4) & $(5)$ & $(6)$ \\
\hline \multirow[t]{2}{*}{$P \& D$} & 0,007 & 0,010 & 0,016 & 0,016 & 0,015 & 0,022 \\
\hline & $(0,412)$ & $(0,441)$ & $(0,367)$ & $(0,521)$ & $(0,522)$ & $(0,434)$ \\
\hline \multirow[t]{2}{*}{$\Delta \ln K$} & 0,036 & $-0,035$ & 0,044 & $-0,028$ & $-0,028$ & $-0,031$ \\
\hline & $(0,151)$ & $(0,683)$ & $(0,128)$ & $(0,747)$ & $(0,746)$ & $(0,754)$ \\
\hline \multirow[t]{2}{*}{$\Delta \ln Y$} & $0,016^{*}$ & $0,020^{*}$ & $0,016^{*}$ & 0,019 & 0,019 & 0,015 \\
\hline & $(0,054)$ & $(0,084)$ & $(0,072)$ & $(0,114)$ & $(0,113)$ & $(0,270)$ \\
\hline \multirow[t]{2}{*}{$\Delta \ln \left(w^{S} / w^{U}\right)$} & 0,005 & 0,009 & 0,005 & 0,009 & 0,009 & $0,028^{* *}$ \\
\hline & $(0,319)$ & $(0,137)$ & $(0,299)$ & $(0,133)$ & $(0,133)$ & $(0,048)$ \\
\hline \multirow{3}{*}{$\begin{array}{c}\text { Instrumentos para } \\
P \& D\end{array}$} & - & - & $R \& D_{t-1}$ & $R \& D_{t-1}$ & $R \& D_{t-1}$ & $R \& D_{t-1}$ \\
\hline & & & & & $R \& D_{t-2}$ & $R \& D_{t-2}$ \\
\hline & & & & & $R \& D_{t-3}$ & $R \& D_{t-3}$ \\
\hline \multirow{4}{*}{$\begin{array}{c}\text { Instrumentos para } \\
\Delta \ln \left(w^{S} / w^{U}\right) \\
\text { Período } \\
N\end{array}$} & - & - & - & - & - & $\Delta \ln \left(w^{S} / w^{U}\right)_{t-1}$ \\
\hline & & & & & & $\Delta \ln \left(w^{S} / w^{U}\right)_{t-2}$ \\
\hline & 1989-97 & 1994-97 & 1989-97 & $1994-97$ & 1994-97 & $1994-97$ \\
\hline & 108 & 48 & 108 & 48 & 48 & 48 \\
\hline
\end{tabular}

Nota: Valores entre parênteses são p-values. Todas as regressões incluem dummies anuais.

*significante a $10 \%,{ }^{* *}$ significante a $5 \%$ 
Tabela A.2

Resultados da estimação de (3) Variável Dependente: $\Delta$ (Emprego relativo)

Qualificados $=$ indivíduos com oito ou mais anos de estudo

\begin{tabular}{|c|c|c|c|c|c|c|}
\hline \multicolumn{7}{|c|}{ Intensidade de $\mathrm{P} \& \mathrm{D}=$ Anpei } \\
\hline & (1) & $(2)$ & $(3)$ & $(4)$ & $(5)$ & $(6)$ \\
\hline \multirow[t]{2}{*}{$P \& D$} & 0,009 & 0,246 & 1,011 & 1,225 & 1,044 & 1,447 \\
\hline & $(0,980)$ & $(0,580)$ & $(0,218)$ & $(0,239)$ & $(0,302)$ & $(0,194)$ \\
\hline \multirow[t]{2}{*}{$\Delta \ln K$} & $0,092^{* *}$ & $-0,021$ & $0,124 * *$ & 0,051 & 0,038 & 0,041 \\
\hline & $(0,016)$ & $(0,848)$ & $(0,007)$ & $(0,706)$ & $(0,776)$ & $(0,776)$ \\
\hline \multirow[t]{2}{*}{$\Delta \ln Y$} & 0,003 & $-0,007$ & 0,005 & $-0,007$ & $-0,007$ & $-0,007$ \\
\hline & $(0,850)$ & $(0,639)$ & $(0,714)$ & $(0,692)$ & $(0,680)$ & $(0,699)$ \\
\hline \multirow{2}{*}{$\Delta \ln \left(w^{S} / w^{U}\right)$} & 0,001 & 0,034 & 0,002 & $0,040^{*}$ & $0,039^{*}$ & $0,091^{*}$ \\
\hline & $(0,956)$ & $(0,111)$ & $(0,910)$ & $(0,085)$ & $(0,088)$ & $(0,090)$ \\
\hline \multirow{3}{*}{$\begin{array}{c}\text { Instrumentos para } \\
P \& D\end{array}$} & - & - & $R \& D_{t-1}$ & $R \& D_{t-1}$ & $R \& D_{t-1}$ & $R \& D_{t-1}$ \\
\hline & & & & & $R \& D_{t-2}$ & $R \& D_{t-2}$ \\
\hline & & & & & $R \& D_{t-3}$ & $R \& D_{t-3}$ \\
\hline \multirow{2}{*}{$\begin{array}{c}\text { Instrumentos para } \\
\Delta \ln \left(w^{S} / w^{U}\right) \\
\text { Período }\end{array}$} & - & - & - & - & - & $\Delta \ln \left(w^{S} / w^{U}\right)_{t-1}$ \\
\hline & & & & & & $\Delta \ln \left(w^{S} / w^{U}\right)_{t-2}$ \\
\hline Período & $1989-97$ & 1994-97 & $1989-97$ & 1994-97 & 1994-97 & $1994-97$ \\
\hline \multirow[t]{3}{*}{$N$} & 126 & 56 & 126 & 56 & 56 & 56 \\
\hline & & ntensida & de de $\mathrm{P}$ & $=\mathrm{Paep}$ & & \\
\hline & (1) & $(2)$ & $(3)$ & (4) & $(5)$ & (6) \\
\hline \multirow[t]{2}{*}{$P \& D$} & 0,027 & $0,042^{*}$ & 0,050 & 0,048 & 0,052 & 0,066 \\
\hline & $(0,158)$ & $(0,093)$ & $(0,183)$ & $(0,289)$ & $(0,249)$ & $(0,180)$ \\
\hline \multirow[t]{2}{*}{$\Delta \ln K$} & $0,150^{* *}$ & 0,019 & $0,170^{* *}$ & 0,026 & 0,031 & 0,063 \\
\hline & $(0,005)$ & $(0,906)$ & $(0,005)$ & $(0,875)$ & $(0,853)$ & $(0,723)$ \\
\hline \multirow[t]{2}{*}{$\Delta \ln Y$} & $-0,004$ & $-0,025$ & $-0,006$ & $-0,026$ & $-0,027$ & $-0,032$ \\
\hline & $(0,828)$ & $(0,243)$ & $(0,750)$ & $(0,243)$ & $(0,232)$ & $(0,188)$ \\
\hline \multirow[t]{2}{*}{$\Delta \ln \left(w^{S} / w^{U}\right)$} & $-0,001$ & 0,034 & $-0,002$ & 0,034 & 0,034 & $0,087^{*}$ \\
\hline & $(0,928)$ & $(0,141)$ & $(0,885)$ & $(0,142)$ & $(0,142)$ & $(0,078)$ \\
\hline \multirow{3}{*}{$\begin{array}{c}\text { Instrumentos para } \\
P \& D\end{array}$} & - & - & $R \& D_{t-1}$ & $R \& D_{t-1}$ & $R \& D_{t-1}$ & $R \& D_{t-1}$ \\
\hline & & & & $R \& D_{t-2}$ & $R \& D_{t-2}$ & \\
\hline & & & & & $R \& D_{t-3}$ & $R \& D_{t-3}$ \\
\hline \multirow{4}{*}{$\begin{array}{c}\text { Instrumentos para } \\
\Delta \ln \left(w^{S} / w^{U}\right) \\
\text { Período }\end{array}$} & - & - & - & - & - & $\Delta \ln \left(w^{S} / w^{U}\right)_{t-1}$ \\
\hline & & & & & & $\Delta \ln \left(w^{S} / w^{U}\right)_{t-2}$ \\
\hline & $1989-97$ & 1994-97 & $1989-97$ & 1994-97 & 1994-97 & $1994-97$ \\
\hline & 108 & 48 & 108 & 48 & 48 & 48 \\
\hline
\end{tabular}

Nota: Valores entre parênteses são p-values. Todas as regressões incluem dummies anuais.

*significante a $10 \%,{ }^{* *}$ significante a $5 \%$ 